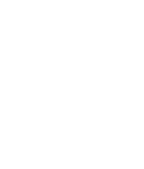

\section{REVIEWS Further}

Click here for quick links to Annual Reviews content online, including:

- Other articles in this volume

- Top cited articles

- Top downloaded articles

- Our comprehensive search

\title{
Heuristic Decision Making
}

\section{Gerd Gigerenzer and Wolfgang Gaissmaier}

Center for Adaptive Behavior and Cognition, Max Planck Institute for Human Development, 14195 Berlin, Germany; email: gigerenzer@mpib-berlin.mpg.de
Annu. Rev. Psychol. 2011.62:451-82

The Annual Review of Psychology is online at psych.annualreviews.org

This article's doi:

10.1146/annurev-psych-120709-145346

Copyright (c) 2011 by Annual Reviews. All rights reserved

0066-4308/11/0110-0451\$20.00

\section{Key Words}

accuracy-effort trade-off, business decisions, ecological rationality, legal decision making, medical decision making, social intelligence

\begin{abstract}
As reflected in the amount of controversy, few areas in psychology have undergone such dramatic conceptual changes in the past decade as the emerging science of heuristics. Heuristics are efficient cognitive processes, conscious or unconscious, that ignore part of the information. Because using heuristics saves effort, the classical view has been that heuristic decisions imply greater errors than do "rational" decisions as defined by logic or statistical models. However, for many decisions, the assumptions of rational models are not met, and it is an empirical rather than an a priori issue how well cognitive heuristics function in an uncertain world. To answer both the descriptive question ("Which heuristics do people use in which situations?") and the prescriptive question ("When should people rely on a given heuristic rather than a complex strategy to make better judgments?"), formal models are indispensable. We review research that tests formal models of heuristic inference, including in business organizations, health care, and legal institutions. This research indicates that $(a)$ individuals and organizations often rely on simple heuristics in an adaptive way, and $(b)$ ignoring part of the information can lead to more accurate judgments than weighting and adding all information, for instance for low predictability and small samples. The big future challenge is to develop a systematic theory of the building blocks of heuristics as well as the core capacities and environmental structures these exploit.
\end{abstract}




\section{Contents}

INTRODUCTION ............... 452

Scope of Review ............... 453

WHAT IS A HEURISTIC? .......... 454

Definition ................... 454

Less-Can-Be-More: Managers'

One-Good-Reason Decisions.... 455

The Adaptive Toolbox ........... 456

WHY HEURISTICS? ............. 456

Accuracy-Effort Trade-Off....... 456

Ecological Rationality ............ 457

METHODOLOGICAL

PRINCIPLES

Comparative Versus Singular

Tests

Test of Individuals Versus

Group Means

Testing the Adaptive Versus

Universal Use of Heuristics .... 459

Prediction Versus Fitting.......... 459

RECOGNITION-BASED

DECISION MAKING .......... 460

Recognition Heuristic ............ 460

Fluency Heuristic .............. 462

Neural Basis of Recognition and Evaluation.............. 463

ONE-REASON DECISION

MAKING ................... 463

One-Clever-Cue Heuristics . . . . . . . 463

Take-the-Best ............... 464

Fast-and-Frugal Trees ........... 467

TRADE-OFF HEURISTICS . . . . . . . 469

Tallying ..................... 469

Mapping Model ............... 470

$1 / N$ Rule ..................... 470

SOCIAL INTELLIGENCE ........ 471

Recognition-Based Decisions....... 471

One-Reason Decision Making...... 472

Trade-Off Heuristics.............. 472

Social Heuristics.............. 472

Moral Behavior ................ 473

CONCLUSIONS ................ 473

\section{INTRODUCTION}

How are decisions made? Three major answers have been proposed: The mind applies logic, statistics, or heuristics. Yet these mental tools have not been treated as equals, each suited to a particular kind of problem, as we believe they should be. Rather, rules of logic and statistics have been linked to rational reasoning and heuristics linked to error-prone intuitions or even irrationality. Since the 1970s, this opposition has been entrenched in psychological research, from the heuristics-and-biases program (Tversky \& Kahneman 1974) to various two-system theories of reasoning (Evans 2008). Deviations from logical or statistical principles became routinely interpreted as judgmental biases and attributed to cognitive heuristics such as "representativeness" or to an intuitive "System 1." The bottom line was that people often rely on heuristics, but they would be better off in terms of accuracy if they did not. As Kahneman (2003) explained in his Nobel Memorial Lecture: "Our research attempted to obtain a map of bounded rationality, by exploring the systematic biases that separate the beliefs that people have and the choices they make from the optimal beliefs and choices assumed in rational-agent models" (p. 1449). In this research, it is assumed that the conditions for rational models hold and can thus define optimal reasoning. The "father" of bounded rationality, Simon (1989), however, asked a fundamentally different question, leading to a different research program.

\footnotetext{
Simon's question: "How do human beings reason when the conditions for rationality postulated by the model of neoclassical economics are not met?" (p. 377)
}

As Simon (1979, p. 500) stressed in his Nobel Memorial Lecture, the classical model of rationality requires knowledge of all the relevant alternatives, their consequences and probabilities, and a predictable world without surprises. These conditions, however, are rarely met for the problems that individuals and organizations face. Savage (1954), known as the founder of modern Bayesian decision theory, called such perfect knowledge small worlds, to be distinguished from large worlds. In large worlds, part 
of the relevant information is unknown or has to be estimated from small samples, so that the conditions for rational decision theory are not met, making it an inappropriate norm for optimal reasoning (Binmore 2009). In a large world, as emphasized by both Savage and Simon, one can no longer assume that "rational" models automatically provide the correct answer. Even small deviations from the model conditions can matter. In fact, small-world theories can lead to disaster when applied to the large world, as Stiglitz (2010) noted with respect to the financial crash of 2008: "It simply wasn't true that a world with almost perfect information was very similar to one in which there was perfect information" (p. 243, emphasis added). And Sorros (2009) concluded that "rational expectations theory is no longer taken seriously outside academic circles" (p. 6).

In recent years, research has moved beyond small worlds such as the ultimatum game and choice between monetary gambles. To test how well heuristics perform in large worlds, one needs formal models of heuristics. Such tests are not possible as long as heuristics are only vaguely characterized by general labels, because labels cannot make the precise predictions that statistical techniques can.

When heuristics were formalized, a surprising discovery was made. In a number of large worlds, simple heuristics were more accurate than standard statistical methods that have the same or more information. These results became known as less-is-more effects: There is an inverse-U-shaped relation between level of accuracy and amount of information, computation, or time. In other words, there is a point where more is not better, but harmful. Starting in the late 1990s, it was shown for the first time that relying on one good reason (and ignoring the rest) can lead to higher predictive accuracy than achieved by a linear multiple regression (Czerlinski et al. 1999, Gigerenzer \& Goldstein 1996) and a three-layer feedforward connectionist network trained using the back propagation algorithm (Brighton 2006, Chater et al. 2003, Gigerenzer \& Brighton 2009). These results put heuristics on par with standard statistical models of "rational" cognition (see Gigerenzer 2008). Simon (1999) spoke of a "revolution in cognitive science, striking a great blow for sanity in the approach to human rationality."

The revolution Simon referred to could not have happened without formal models and the power of modern computers. Moreover, it is a "revolution" in the original sense of the term, building on earlier demonstrations of the robust beauty of simple models. These include Dawes \& Corrigan (1974) and Einhorn \& Hogarth (1975), who showed that simple equal weights predict about as well as-and sometimes better than-multiple regression with "optimal" beta weights. Their important work has not received the recognition it deserves and is not even mentioned in standard textbooks in econometrics (Hogarth 2011).

Although the study of heuristics has been typically considered as purely descriptive, lessis-more effects open up a prescriptive role for heuristics, resulting in two research questions:

Description: Which heuristics do people use in which situations?

Prescription: When should people rely on a given heuristic rather than a complex strategy to make more accurate judgments?

\section{Scope of Review}

We review a field that is in a fundamental transition, focusing on the major new ideas. The literature on heuristics does not speak with one voice, and we do not attempt to cover it exhaustively. Rather than presenting a patchwork of ideas to the reader, we organize this review within a theoretical framework and restrict it to (a) formal models of heuristics and (b) inferences rather than preferences.

The first restriction excludes explanation by mere labels but also by verbally stated processes that have not been formalized, such as the tools-to-theories heuristic in scientific discovery (Gigerenzer 1991). Formal models allow rigorous tests of both descriptive and prescriptive questions. "Inference" refers to tasks
Small world: a

situation in which all relevant alternatives, their consequences, and probabilities are known, and where the future is certain, so that the optimal solution to a problem can be determined

Large world: a situation in which some relevant information is unknown or must be estimated from samples, and the future is uncertain, violating the conditions for rational decision theory

Less-is-more effects: when less information or computation leads to more accurate judgments than more information or computation

Errata 
Heuristics: strategies that ignore information to make decisions faster, more frugally, and/or more accurately than more complex methods for which a unique criterion exists, whereas "preference" (or preferential choice) refers to tasks where no such criteria exist, as in matters of taste. The advantage of studying inference is that the accuracy of a strategy can be determined. At the same time, we agree with Weber \& Johnson (2009) that inferences and preferences draw on the same cognitive processes; in fact, most heuristics covered in this review can be used for preferential choice as well, as illustrated with examples from consumer choice and health. Note that the general term "decision making" is used here to cover both inferences and preferences.

We begin with a brief, incomplete history (for more, see Groner et al. 1983), define the term heuristic, and provide an illustration of the use of heuristics in organizations, including an empirical demonstration of a less-is-more effect.

\section{WHAT IS A HEURISTIC?}

The term heuristic is of Greek origin and means, "serving to find out or discover." Einstein included the term in the title of his Nobel prize-winning paper from 1905 on quantum physics, indicating that the view he presented was incomplete but highly useful (Holton 1988, pp. 360-361). Max Wertheimer, who was a close friend of Einstein, and his fellow Gestalt psychologists spoke of heuristic methods such as "looking around" to guide search for information. The mathematician George Polya distinguished heuristics from analytical methods: For instance, heuristics are needed to find a proof, whereas analysis is for checking a proof. Simon and Allen Newell, a student of Polya, developed formal models of heuristics to limit large search spaces. Luce (1956), Tversky (1972), Dawes (1979), and others studied models of heuristics, such as lexicographic rules, elimination-by-aspect, and equal-weight rules. Payne and colleagues (1993) provided evidence for the adaptive use of these and other heuristics in their seminal research. Similarly, behavioral biologists studied experimentally the rules of thumb (their term for heuristics) that animals use for choosing food sites, nest sites, or mates
(Hutchinson \& Gigerenzer 2005). After an initial phase dominated by logic, researchers in artificial intelligence (AI) began to study heuristics that can solve problems that logic and probability cannot, such as NP-complete (computationally intractable) problems. While AI researchers began to study how heuristics make computers smart, psychologists in the 1970s became interested in demonstrating human reasoning errors, and they used the term heuristic to explain why people make errors. This change in the evaluation of heuristics went hand-in-hand with replacing models of heuristics by general labels, such as "availability" and, later, "affect." Unlike in biology and AI, heuristics became tied to biases, whereas the content-free laws of logic and probability became identified with the principles of sound thinking (Kahneman 2003, Tversky \& Kahneman 1974). The resulting heuristicsand-biases program has had immense influence, contributing to the emergence of behavioral economics and behavioral law and economics.

\section{Definition}

Many definitions of heuristics exist. Kahneman \& Frederick (2002) proposed that a heuristic assesses a target attribute by another property (attribute substitution) that comes more readily to mind. Shah \& Oppenheimer (2008) proposed that all heuristics rely on effort reduction by one or more of the following: (a) examining fewer cues, $(b)$ reducing the effort of retrieving cue values, $(c)$ simplifying the weighting of cues, $(d)$ integrating less information, and (e) examining fewer alternatives. Although both attribute substitution and effort reduction are involved, attribute substitution is less specific because most inference methods, including multiple regression, entail it: An unknown criterion is estimated by cues. For the purpose of this review, we adopt the following definition:

\footnotetext{
A heuristic is a strategy that ignores part of the information, with the goal of making decisions more quickly, frugally, and/or accurately than more complex methods.
} 
Let us explain the terms. Heuristics are a subset of strategies; strategies also include complex regression or Bayesian models. The part of the information that is ignored is covered by Shah and Oppenheimer's list of five aspects. The goal of making judgments more quickly and frugally is consistent with the goal of effort reduction, where "frugal" is often measured by the number of cues that a heuristic searches. Of course, there is no strict dichotomy between heuristic and nonheuristic, as strategies can ignore more or less information. The goal of making judgments more accurately by ignoring information is new. It goes beyond the classical assumption that a heuristic trades off some accuracy for less effort. Unlike the two-system models of reasoning that link heuristics to unconscious, associative, and error-prone processes, no such link is made in this review. Every heuristic reviewed in this article can also be relied upon consciously and is defined as a rule. The amount of error it generates can be measured and compared to other strategies.

Consider the following illustration.

\section{Less-Can-Be-More: Managers' One-Good-Reason Decisions}

Commercial retailers need to distinguish those customers who are likely to purchase again in a given time frame (active customers) from those who are not (inactive customers). These companies have a large database containing the amount, kind, and date of every customer's previous purchases. Based on this information, how can an executive predict which customers will be active in the future?

Statistically sophisticated academics might opt for a Bayesian analysis, regression analysis, or some other optimizing strategy to predict the probability that a customer with a given purchase history is active at some future time. Researchers in business share this vision, and the state-of-the-art approach is the Pareto/NBD model (negative binomial distribution; Schmittlein \& Peterson 1994). This model assumes that purchases follow a Poisson process with a purchase parameter $\lambda$, that customer lifetimes follow an exponential distribution with a dropout rate parameter $\mu$, and that, across customers, purchase and dropout rates are distributed according to a gamma distribution. However, most managers in Europe, North America, Japan, Brazil, and India rely on "intuitive" heuristics rather than on this or similar statistical forecasting methods (Parikh 1994). Wübben \& Wangenheim (2008) reported that experienced managers use a simple recency-of-last-purchase rule:

Hiatus heuristic: If a customer has not purchased within a certain number of months (the hiatus), the customer is classified as inactive; otherwise, the customer is classified as active.

The managers of an apparel retailer and an airline relied on nine months as the hiatus, whereas the hiatus of an online CD retailer was six months. Note that by relying on recency only, the managers ignore information such as the frequency and the spacing of previous purchases. Yet how accurate is the heuristic compared to the Pareto/NBD model? To investigate this question, the Pareto/NBD model was allowed to estimate its parameters from 40 weeks of data and was tested over the following 40 weeks. The hiatus heuristic does not need to estimate any parameters. For the apparel retailer, the hiatus heuristic correctly classified $83 \%$ of customers, whereas the Pareto/NBD model classified only $75 \%$ correctly. For the airline, the score was $77 \%$ versus $74 \%$, and for the online CD business, the two methods tied at 77\% (Wübben \& Wangenheim 2008). Similar results were found for forecasting future best customers and for a second complex statistical model.

This study demonstrated empirically a lessis-more effect: The complex model had all the information the simple heuristic used and more, performed extensive estimations and computations, but nevertheless made more errors. The study also showed how important it is to formalize a heuristic so that its predictions can be tested and compared to competing models. 


\section{Adaptive toolbox:}

the cognitive

heuristics, their

building blocks (e.g., rules for search, stopping, decision), and the core capacities (e.g., recognition memory) they exploit

Ecological rationality: the study of ecological rationality investigates in which environments a given strategy is better than other strategies (better-not best-because in large worlds the optimal strategy is unknown)

Accuracy-effort trade-off: the traditional explanation why people use heuristics, assuming that effort is traded against accuracy. Not generally true (see less-is-more effects)

\section{The Adaptive Toolbox}

Formal models of heuristics represent progress over labels, but precision alone is not enough to build a science of heuristics. For instance, behavioral biology has experimentally identified various rules of thumb that animals use, which often look like curiosities in the absence of an overarching theory (Hutchinson \& Gigerenzer 2005). Further progress requires a theoretical framework that reaches beyond a list of heuristics. One step toward such a theory is to look for common building blocks, from which the various heuristics are constructed as an organizing principle. This would allow reducing the larger number of heuristics to a smaller number of components, similar to how the number of chemical elements in the periodic table is built from a small number of particles. Three building blocks have been proposed (Gigerenzer et al. 1999):

1. Search rules specify in what direction the search extends in the search space.

2. Stopping rules specify when the search is stopped.

3. Decision rules specify how the final decision is reached.

For instance, the hiatus heuristic searches for recency-of-last-purchase information; stops when it is found, ignoring further information; and uses a nine-month threshold to make the decision. Similarly, Simon's (1955) satisficing heuristic searches through options in any order, stops as soon the first option exceeds an aspiration level, and chooses this option. Many but not all heuristics are composed of these three building blocks; thus, the list of building blocks is incomplete.

The collection of heuristics and building blocks an individual or a species has at its disposal for constructing heuristics, together with the core mental capacities that building blocks exploit, has been called the adaptive toolbox (Gigerenzer et al. 1999). Core capacities include recognition memory, frequency monitoring, object tracking, and the ability to imitate. These vary systematically between species and individuals. Heuristics can be fast and frugal only because the core capacities are already in place.

How are heuristics selected for a given problem? Although some authors implied that the selection problem is unique to heuristics (Glöckner et al. 2010, Newell 2005), it equally applies to statistical models of mind. There are many such models. Even if one proposes that the mind has only one tool in its statistical toolbox, such as Bayes, regression, or neural network, the strategy selection problem translates into the question of how parameter values are selected for each new problem (Marewski 2010).

Several principles appear to guide learning which strategy to select. First, heuristics and their underlying core capacities can be (partly) hardwired by evolution, as it appears to be in bees' collective decision about the location of a new hive (Seeley 2001) and in perceptual mechanisms for inferring the extension of objects in three-dimensional space (Kleffner \& Ramachandran 1992). The second selection principle is based on individual learning; a formal model is Rieskamp \& Otto's (2006) strategy selection learning theory. Third, heuristics can be selected and learned by social processes, as in imitation and explicit teaching of heuristics (e.g., Snook et al. 2004). Finally, the content of individual memory determines in the first place which heuristics can be used, and some heuristics' very applicability appears to be correlated with their "ecological rationality" (see below). For instance, the fluency heuristic is most likely to be applicable in situations where it is also likely to succeed (Marewski \& Schooler 2010).

\section{WHY HEURISTICS?}

Two answers have been proposed to the question of why heuristics are useful: the accuracyeffort trade-off, and the ecological rationality of heuristics.

\section{Accuracy-Effort Trade-Off}

The classical explanation is that people save effort with heuristics, but at the cost of accuracy 
(Payne et al. 1993, Shah \& Oppenheimer 2008). In this view, humans and other animals rely on heuristics because information search and computation cost time and effort; heuristics tradeoff some loss in accuracy for faster and more frugal cognition.

There are two interpretations of this tradeoff: (a) Rational trade-offs. Not every decision is important enough to warrant spending the time to find the best course of action; thus, people choose shortcuts that save effort. The program on the adaptive decision maker (Payne et al. 1993 ) is built on the assumption that heuristics achieve a beneficial trade-off between accuracy and effort. Here, relying on heuristics can be rational in the sense that costs of effort are higher than the gain in accuracy. (b) Cognitive limitations. Capacity limitations prevent us from acting rationally and force us to rely on heuristics, which are considered a source of judgmental errors.

The accuracy-effort trade-off is regularly touted as a potentially universal law of cognition. Yet the study on the hiatus heuristic illustrated that this assumption is not generally correct. The hiatus heuristic saves effort compared to the sophisticated Pareto/NBD model, but is also more accurate: a less-is-more effect.

\section{Ecological Rationality}

Less-is-more effects require a new conception of why people rely on heuristics. The study of the ecological rationality of heuristics, or strategies in general, is such a new framework: "A heuristic is ecologically rational to the degree that it is adapted to the structure of the environment" (Gigerenzer et al. 1999, p. 13). Smith (2003) used this definition in his Nobel lecture and generalized it from heuristics to markets and institutions. The study of ecological rationality fleshes out Simon's scissors analogy: "Human rational behavior (and the rational behavior of all physical symbol systems) is shaped by a scissors whose two blades are the structure of task environments and the computational capabilities of the actor" (Simon 1990, p. 7). If one looks only at one blade, cognition, one cannot understand why and when it succeeds or fails. The study of ecological rationality addresses two related questions: How does cognition exploit environmental structures, and how does it deal with error?

Exploiting environmental structure. In which environments will a given heuristic succeed, and in which will it fail? Environmental structures that have been identified include (Todd et al. 2011):

1. Uncertainty: how well a criterion can be predicted.

2. Redundancy: the correlation between cues.

3. Sample size: number of observations (relative to number of cues).

4. Variability in weights: the distribution of the cue weights (e.g., skewed or uniform).

For instance, heuristics that rely on only one reason, such as the hiatus heuristic and takethe-best heuristic (see below), tend to succeed (relative to strategies that rely on more reasons) in environments with (a) moderate to high uncertainty (Hogarth \& Karelaia 2007) and (b) moderate to high redundancy (Dieckmann \& Rieskamp 2007). For customer activity, uncertainty means that it is difficult to predict future purchases, and redundancy might be reflected in a high correlation between length of hiatus and spacing of previous purchases. The study of ecological rationality results in comparative statements of the kind "strategy $X$ is more accurate (frugal, fast) than $Y$ in environment $E$ " or in quantitative relations between the performance of strategy $X$ when the structure of an environment changes (e.g., Baucells et al. 2008, Karelaia 2006, Martignon \& Hoffrage 2002). Specific findings are introduced below.

Dealing with error. In much research on reasoning, a bias typically refers to ignoring part of the information, as in the base rate fallacy. This can be captured by the equation:

$$
\text { Error }=\text { bias }+\varepsilon,
$$

where $\varepsilon$ is an irreducible random error. In this view, if the bias is eliminated, good 
inferences are obtained. In statistical theory (Geman et al. 1992), however, there are three sources of errors:

$$
\text { Error }=\text { bias }+ \text { variance }+\varepsilon,
$$

where bias refers to a systematic deviation between a model and the true state, as in Equation 1. To define the meaning of variance, consider 100 people who rely on the same strategy, but each one has a different sample of observations from the same population. Because of sampling error, the 100 inferences may not be the same. Across samples, bias is the difference between the mean prediction and the true state of nature, and variance is the expected squared deviation around this mean. To illustrate, the nine-month hiatus heuristic has a bias but zero variance, because it has no free parameters to adjust to specific samples. In contrast, the Pareto/NBD model has free parameters and is likely to suffer from both variance and bias. Variance decreases with increasing sample size, but also with simpler strategies that have fewer free parameters (and less flexible functional forms; Pitt et al. 2002). Thus, a cognitive system needs to draw a balance between being biased and flexible (variance) rather than simply trying to eliminate bias. In the extreme, as illustrated by the nine-month hiatus, the total elimination of variance at the price of higher bias can lead to better inferences. This "bias-variance dilemma" helps to explicate the rationality of simple heuristics and how less can be more (Brighton \& Gigerenzer 2008, Gigerenzer \& Brighton 2009).

The study of ecological rationality is related to the view that human cognition is adapted to its past environment (Cosmides \& Tooby 2006), yet it should not be confused with the biological concept of adaptation. A match between a heuristic and an environmental structure does not imply that the heuristic evolved because of that environment (Hutchinson \& Gigerenzer 2005). The distinction between ecological and logical rationality is linked to that between correspondence and coherence (Hammond 2007), but it is not identical. If correspondence means achieving a goal in the world rather than cohering to a rule of logic, correspondence and ecological rationality refer to similar goals-although the study of the latter adds a mathematical analysis of the relation between heuristic and environment. If correspondence, however, means that the mental representation corresponds to the world, as in a fairly accurate mental model or in Shepard's (2001) view of the mind as a mirror reflecting the world, then ecological rationality is different. A heuristic is functional, not a veridical copy of the world.

Ecological rationality does not mean that all people are perfectly adapted to their environment. As Simon (1992) noted, if that were the case, one would only need to study the environment to predict behavior; the study of heuristics would be obsolete.

\section{METHODOLOGICAL PRINCIPLES}

Formal models of heuristics are indispensable for progress, yet remain the exception in psychology. Much of the research first documents an error of judgment and thereafter attributes it to a heuristic. In a widely cited experiment, Tversky \& Kahneman (1973) reported that certain letters were falsely judged to occur more frequently in the first than the third position in English words. They attributed this error to the availability heuristic: Words with a letter in the first position come to mind more easily. Note that availability was introduced after the fact, without any independent measure or test. Once the heuristic is formalized, conclusions change. Sedlmeier and colleagues (1998) defined and modeled the two most common meanings of availability - the speed of retrieval of the first word and the number of retrieved words within a constant time period. Neither version of the availability heuristic could predict participants' frequency estimates. Instead, estimated frequencies were best predicted by actual frequencies, consistent with the classical findings by Attneave (1953). Formal models protect against the seductive power of general labels. 
We are concerned about the replacement of formal models by general labels in parts of psychology. For instance, Tversky's (1977) seminal model of similarity makes testable predictions (e.g., the asymmetry of similarity), whereas the widely cited label "representativeness" can predict little but is so flexible that it is consistent with many judgments, including opposite intuitions (Ayton \& Fischer 2004). Similarly, research on the adaptive decision maker (Payne et al. 1993) and the adaptive toolbox (Gigerenzer et al. 1999) has studied formal models of heuristics, which have been ignored in two-system theories of reasoning in favor of a "System 1" (Evans 2008). The problem with two-system theories "is the lack of any predictive power and the tendency to employ them as an after-the-fact explanation" (Keren \& Schul 2009, p. 544). Moving backward from existing models to labels is a rare event in science, which typically proceeds in the opposite direction.

The study of formal models entails four methodological principles.

\section{Comparative Versus Singular Tests}

All models are wrong. But some predict better than others and lead to novel questions. Therefore, tests of cognitive strategies need to be comparative, that is, test several models. This differs from the widespread practice of null hypothesis testing, where only one model (the null) is specified.

\section{Test of Individuals Versus Group Means}

Numerous studies have documented systematic individual differences in the use of heuristics (e.g., Lee \& Cummins 2004, Nosofsky \& Bergert 2007), including in old age (Mata et al. 2007). In the presence of individual differences, tests of group mean differences can be highly misleading (see Pachur et al. 2008).

\section{Testing the Adaptive Versus Universal Use of Heuristics}

Research has shifted from asking whether people use one heuristic in all situations to asking whether heuristics are applied in situations where these are ecologically rational. For instance, Bröder began by asking whether all people use the take-the-best heuristic all the time, but soon asked whether people rely on take-the-best in situations where it is ecologically rational, for instance, when cue validities are highly skewed (Bröder \& Schiffer 2003, 2006).

\section{Prediction Versus Fitting}

Prediction takes place when the data have not yet been observed and a model with fixed parameter values is used to predict them; fitting takes place when the data have already been observed and the parameters of a model are chosen so that they maximize the fit (such as $\mathrm{R}^{2}$ ). In general, the more free parameters a model has, the better the fit, but this does not hold for predictions. In a large world where parameters need to be estimated from small or unreliable samples, the function between predictive accuracy and the flexibility of a model (e.g., number of free parameters) is typically inversely $U_{-}$ shaped. Both too few and too many parameters can hurt performance (Pitt et al. 2002). Competing models of strategies should be tested for their predictive ability, not their ability to fit already known data.

In the next sections, we review four classes of heuristics. The first class exploits recognition memory, the second relies on one good reason only (and ignores all other reasons), the third weights all cues or alternatives equally, and the fourth relies on social information. As mentioned in the introduction, formal models of heuristics allow asking two questions: whether they can describe decisions, and whether they can prescribe how to make better decisions than, say, a complex statistical method. The prescriptive question is particularly relevant for organizations, from business to health care. Organizations seem ideally suited to the application of heuristics because of the inherent uncertainty and the pressure to act quickly. One might therefore presume that plenty of studies have investigated fast-and-frugal heuristics in 


\section{Recognition-based} decisions: a class of heuristics that bases judgments on recognition information only, ignoring other cues (e.g., recognition and fluency heuristic)

$$
\alpha=C /(C+W)
$$

where $C$ is the number of correct inferences the recognition heuristic would make, computed across all pairs in which one alternative is recognized and the other is not, and $W$ is the number of wrong inferences.

A number of studies addressed the question of whether people rely on the recognition heuristic in an ecologically rational way. For instance, name recognition of Swiss cities is a valid predictor of their population $(\alpha=0.86)$ but not their distance from the center of Switzerland $(\alpha=0.51)$. Pohl (2006) reported that $89 \%$ of inferences accorded with the model in judgments of population, compared to only $54 \%$ in judgments of the distance. More generally, there is a positive correlation of $r=0.64$ between the recognition validity and the proportion of judgments consistent with the recognition heuristic across 11 studies (Pachur et al. 2011). Similarly, old and young people alike adjust their reliance on the recognition heuristic between environments with high versus low recognition validities, even though old people have poorer recognition memory (Pachur et al. 2009).

The recognition heuristic is a model that relies on recognition only. This leads to the testable prediction that people who rely on it will ignore strong, contradicting cues (so-called noncompensatory inferences). Several studies that taught participants between one and three contradicting cues, typically of higher validity than $\alpha$ (Newell \& Fernandez 2006; Pachur et al. 2008; Richter \& Späth 2006, experiment 3), reported that mean accordance rates decreased. A reanalysis of these studies at an individual level, however, showed that typically about half of the participants consistently followed the recognition heuristic in every single trial, even in the presence of up to three contradicting cues (Pachur et al. 2008).

The model of the recognition heuristic does not distinguish between pairs where the model leads to a correct inference and pairs where it leads to a wrong inference. However, the mean accordance rates were $90 \%$ and $74 \%$, respectively (Pohl 2006, Hilbig \& Pohl 2008). Together with the effect of contradicting cues, this result indicated that some people did not follow the recognition heuristic, although the overall accordance rates remain high. Various authors concluded that people relied on a compensatory strategy, such as weighting and adding of all cues (e.g., Hilbig \& Pohl 2008, Oppenheimer 2003). None of the studies above, however, 
formulated and tested a compensatory strategy against the recognition heuristic, leaving the strategies that participants relied on unknown. One study since tested five compensatory models and found that none could predict judgments better than the simple model of the recognition heuristic (Marewski et al. 2010).

The recognition heuristic model also makes another bold prediction:

If $\alpha>\beta$, and $\alpha, \beta$ are independent of $n$, then a less-is-more effect will be observed.

Here, $\beta$ is the knowledge validity, measured as $C /(C+W)$ for all pairs in which both alternatives are recognized, and $n$ is the number of alternatives an individual recognizes. A less-is-more effect means that the function between accuracy and $n$ is inversely $\mathrm{U}$-shaped rather than monotonically increasing. Some studies reported less-is-more effects empirically among two, three, or four alternatives (Frosch et al. 2007, Goldstein \& Gigerenzer 2002) and in group decisions (Reimer \& Katsikopoulos 2004), whereas others failed to do so (Pachur \& Biele 2007, Pohl 2006), possibly because the effect is predicted to be small [see Katsikopoulos (2010) for an excellent analysis of the evidence]. Using a signal detection analysis, Pleskac (2007) showed how the less-is-more effect depends on the false alarms and miss rates in the recognition judgments.

Dougherty et al. (2008) criticized the model of the recognition heuristic for treating recognition as binary input (threshold model) rather than continuously. In contrast, Bröder \& Schütz (2009) argued that the widespread critique of threshold models is largely invalid. In a reanalysis of 59 published studies, they concluded that threshold models in fact fit the data better in about half of the cases.

Predicting Wimbledon. Although much of the work has addressed the descriptive question of what proportion of people rely on the heuristic when it is ecologically rational, the prescriptive question is how well the heuristic can compete with well-established forecasting instruments (Goldstein \& Gigerenzer 2009). For instance, Serwe \& Frings (2006) reported that collective recognition of amateur players (who knew only half of the contestants) turned out to be a better predictor of the 2004 Wimbledon tennis match outcomes (72\% correct) than did the Association of Tennis Professionals (ATP) Entry Ranking (66\%), ATP Champions Race (68\%), and the seeding of the Wimbledon experts (69\%). Scheibehenne $\&$ Bröder (2007) found the same surprising result for Wimbledon 2006.

\section{Predicting elections. Gaissmaier \&} Marewski (2010) put the recognition heuristic to a test in predicting federal and state elections in Germany. Surprisingly, forecasts based on name recognition were almost as accurate as interviewing voters about their voting intentions. This particularly held true when predicting the success of small parties, for which no polls are usually available because those polls would require huge samples. In contrast to surveys of voting intentions, recognition-based forecasts can be computed from small, "lousy" samples.

Investment. In three studies on predicting the stock market, Ortmann et al. (2008) reported that recognition-based portfolios (the set of most-recognized options), on average, outperformed managed funds such as the Fidelity Growth Fund, the market (Dow or Dax), chance portfolios, and stock experts. In contrast, Boyd (2001) found no such advantage when he used college students' recognition of stocks rather than that of the general public. It is imperative to understand why and under what conditions this simple heuristic can survive in financial markets without making a systematic market analysis. This remains an open question.

Consumer choice. The recognition heuristic could be a first step in consideration set formation (Marewski et al. 2010), as it allows the choice set to be quickly reduced. This idea is consistent with research that suggests that priming a familiar brand increases the probability that it will be considered for purchase (e.g., Coates et al. 2004). Brand recognition can be even more important than attributes that are a 
more direct reflection of quality. For instance, in a blind test, most people preferred a jar of high-quality peanut butter to two alternative jars of low-quality peanut butter. Yet when a familiar brand label was attached to one of the low-quality jars, the preferences changed. Most (73\%) now preferred the jar with the label they recognized, and only $20 \%$ preferred the unlabeled jar with the high-quality peanut butter (Hoyer \& Brown 1990). Brand recognition may well dominate the taste cues, or the taste cues themselves might even be changed by brand recognition-people "taste" the brand name.

\section{Fluency Heuristic}

The recognition heuristic is mute about the underlying recognition process, just as Bayes' rule is mute about source of prior probabilities. Dougherty et al. (2008) argued that it needs to be embedded in a theory of the recognition process. Schooler \& Hertwig (2005) implemented the heuristic based on the ACT-R (Adaptive Control of Thought-Rational) model of memory, which showed how forgetting - a process often seen as nuisance and handicap-can be functional in the context of inference, generating less-is-more effects. In this same work, the fluency heuristic was formulated for situations when both alternatives are recognized, that is, when the recognition heuristic cannot be applied:

Fluency heuristic: If both alternatives are recognized but one is recognized faster, then infer that this alternative has the higher value with respect to the criterion.

The fluency heuristic builds on earlier work on fluency (Jacoby \& Dallas 1981). For instance, fluent processing that stems from previous exposure can increase the perceived truth of repeated assertions (Hertwig et al. 1997) and the perceived fame of names (Jacoby et al. 1989), and it is related to the mere exposure effect (Zajonc 1968). People's sense of fluency has been reported to predict the performance of stocks (Alter \& Oppenheimer 2006).
By formalizing the fluency heuristic, Schooler \& Hertwig (2005) clearly defined the difference between the recognition and fluency heuristics and contributed to the progress in replacing verbal labels with computational models. The fluency heuristic is ecologically rational if the speed of recognition is correlated with the criterion, that is, the fluency validity $>0.5$. Hertwig et al. (2008) reported that the validity of fluency for predicting variables such as sales figures and wealth was always lower than recognition validity, although always above chance. Subsequently, they showed that people can accurately tell the difference between two recognition latencies if the difference exceeded $100 \mathrm{~ms}$, and that across three environments, the mean proportions of inferences consistent with the fluency heuristic were $74 \%, 63 \%$, and $68 \%$, respectively. Accordance rates were as high as $82 \%$ when differences in recognition latencies were large. Deriving the fluency heuristic's prediction for individual people and individual items is a strong test. Yet it is not how the impact of fluency is commonly tested in social and cognitive psychology, where researchers tend to manipulate fluency experimentally and observe the consequences.

Fluency also plays a role when alternatives are not given (as in a two-alternative choice) but need to be generated from memory. Johnson \& Raab (2003) proposed a variant of the fluency heuristic when alternatives are sequentially retrieved rather than simultaneously perceived:

Take-the-first heuristic: Choose the first alternative that comes to mind.

Johnson \& Raab (2003) showed experienced handball players video sequences from a professional game and asked what they would have done-e.g., pass the ball to the player at the left or take a shot. On average, the first option that came to mind was better than later options and when more time was given to inspect the situation. This result was replicated for basketball players (Hepler 2008). Klein's (2004) recognition-primed decision model for 
expertise appears to be closely related to the take-the-first heuristic.

\section{Neural Basis of Recognition and Evaluation}

Although a number of studies have shown that people do not automatically use the recognition heuristic when it can be applied, it is less clear how this evaluation process can be modeled. A functional magnetic resonance imaging study tested whether the two processes, recognition and evaluation, can be separated on a neural basis (Volz et al. 2006). Participants were given two tasks: The first involved only a recognition judgment ("Have you ever heard of Modena? Milan?"), while the second involved an inference in which participants could rely on the recognition heuristic ("Which city has the larger population: Milan or Modena?”). For mere recognition judgments, activation in the precuneus, an area that is known from independent studies to respond to recognition confidence (Yonelinas et al. 2005), was reported. In the inference task, precuneus activation was also observed, as predicted, and activation was detected in the anterior frontomedian cortex (aFMC), which has been linked in earlier studies to evaluative judgments and self-referential processing. The aFMC activation could represent the neural basis of this evaluation of ecological rationality. Furthermore, the neural evidence suggests that the recognition heuristic may be relied upon by default, consistent with the finding that response times were considerably faster when participants' inferences followed the recognition heuristic than when they did not (Pachur \& Hertwig 2006, Volz et al. 2006).

\section{ONE-REASON DECISION MAKING}

Whereas the recognition and fluency heuristics base decisions on recognition information, other heuristics rely on recall. One class looks for only one "clever" cue and bases its decision on that cue alone. The hiatus heuristic is one example. A second class involves sequential search through cues, and it may search for more than one cue but also bases its decision on only one. Examples include lexicographic rules (Fishburn 1974, Luce 1956) and elimination-by-aspect (Tversky 1972). These heuristics were originally developed for preferences; here, we focus on models of inferences.

\section{One-Clever-Cue Heuristics}

Many animal species appear to rely on a single "clever" cue for locating food, nest sites, or mates. For instance, in order to pursue a prey or a mate, bats, birds, and fish do not compute trajectories in three-dimensional space, but simply maintain a constant optical angle between their target and themselves-a strategy called the gaze heuristic (Gigerenzer 2007, Shaffer et al. 2004). In order to catch a fly ball, baseball outfielders and cricket players rely on the same kind of heuristics rather than trying to compute the ball's trajectory (McLeod \& Dienes 1996). Similarly, to choose a mate, a peahen investigates only three or four of the peacocks displaying in a lek and chooses the one with the largest number of eyespots (Petrie \& Halliday 1994).

When are one-clever-cue heuristics ecologically rational? The answer is not entirely clear at this point in time, but candidates are environments where the variability of cue weights and redundancy is moderate to high and sample size is small (see Hogarth \& Karelaia 2007, Katsikopoulos et al. 2010, McGrath 2008).

Geographic profiling. The task of geographic profiling is to predict where a serial criminal is most likely to live given the sites of the crimes. Typically, geographical profiling is performed by sophisticated statistical software programs, such as CrimeStat, that calculate a probability distribution across possible locations. Snook and colleagues (2005) were among the first to challenge the "complexity equals accuracy" assumptions in the field of profiling. They tested the circle heuristic, which predicts the criminal's most likely location in the center of a
One-reason

decisions: a class of heuristics that bases judgments on one good reason only, ignoring other cues (e.g., take-the-best and hiatus heuristic) 
circle drawn through the two most distant sites of crime. It relies on one cue only, the largest distance. In a comparison with 10 other profiling strategies, the heuristic predicted the locations best. Complex profiling strategies appear to become more accurate if the number of crime locations known is nine or higher. Snook et al. (2004) taught two heuristics (including the circle heuristic) to laypeople in criminology and reported that after a single session, laypeople became about as accurate in predicting offender locations as the CrimeStat algorithm. These results led to a heated debate with proponents of optimization algorithms in profiling (e.g., Rossmo 2005).

\section{Take-the-Best}

The take-the-best heuristic is a model of how people infer which of two alternatives has a higher value on a criterion, based on binary cue values retrieved from memory. For convenience, the cue value that signals a higher criterion value is 1 , and the other cue value is 0 . Take-the-best consists of three building blocks:

1. Search rule: Search through cues in order of their validity.

2. Stopping rule: Stop on finding the first cue that discriminates between the alternatives (i.e., cue values are 1 and 0 ).

3. Decision rule: Infer that the alternative with the positive cue value (1) has the higher criterion value.

Take-the-best simplifies decision making by stopping after the first cue and ordering cues unconditionally according to validity $v$, which is given by:

$$
v=C /(C+W),
$$

where $C$ is the number of correct inferences when a cue discriminates, and $W$ is the number of wrong inferences. Alternative search rules such as success (Martignon \& Hoffrage 2002, Newell et al. 2004) and discrimination (Gigerenzer \& Goldstein 1996) have been investigated. Todd \& Dieckmann (2005) studied alternative simple principles for learning cue orders. Karelaia (2006) showed that a "confirmatory" stopping rule-stop after two cues are found that point to the same alternative-leads to remarkably robust results across varying cue orders, which is ecologically rational in situations where the decision maker knows little about the validity of the cues.

A striking discovery was that take-thebest can predict more accurately than linear multiple regression models (Czerlinski et al. 1999). It can even predict more accurately than complex nonlinear strategies. Figure 1 shows the predictive accuracy of an exemplar-based model (nearest-neighbor classifier), Quinlan's decision-tree induction algorithm $\mathrm{C} 4.5$, and classification and regression trees (CARTs), compared to take-the-best. In both tasks, and across most sample sizes, take-the-best achieves higher predictive accuracy than each of the three complex strategies (Brighton \& Gigerenzer 2011). This is not to say that relying on one good reason is always better, but the result in Figure $\mathbf{1}$ is the most frequently obtained in a total of 20 environments. Note that CARTs have been designed to be robust against estimation error (variance) due to small samples and other factors. These complex algorithms can mimic the outcome of take-the-best in the sense that they are models that include takethe-best as a special case. Yet, although their greater flexibility leads to better fit of known data, more general models do not necessarily lead to better predictions of unknown data.

As noted above, take-the-best orders cues unconditionally, unlike the other models in Figure 1. Ordering cues conditionally, that is, taking their interdependencies into account, may seem a more rational strategy. In fact, in a small world where all cue validities are perfectly known, conditional validity leads to higher (or at least equal) accuracy than unconditional validity (Schmitt \& Martignon 2006). However, in large worlds as in Figure 1, where the cue order needs to be estimated from samples, this no longer holds. If one makes take-thebest more sophisticated by ordering cues conditionally (greedy take-the-best), the predictive accuracy drops to the level of the complex 


\section{City Populations}

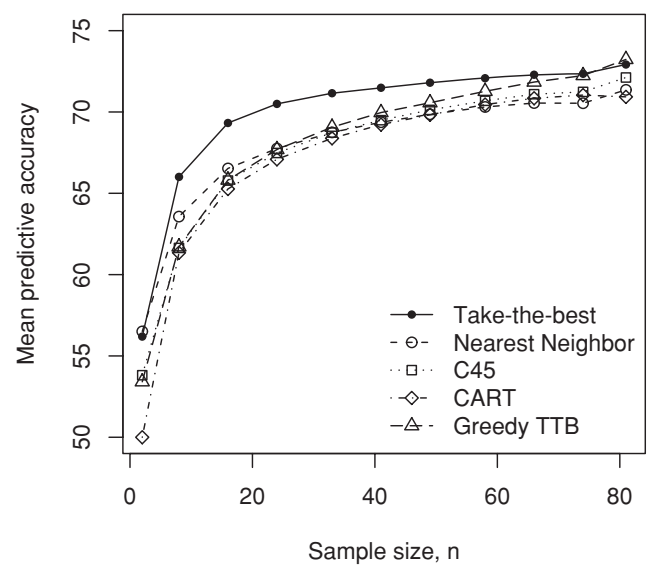

Mammal Lifespans

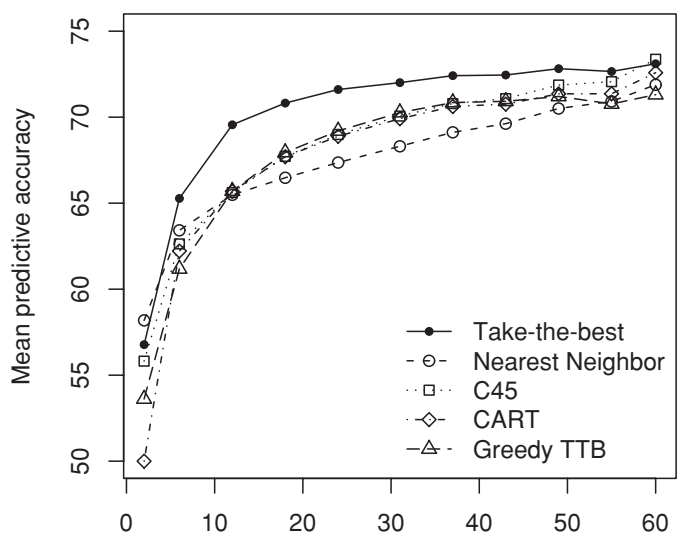

Sample size, $n$

Figure 1

A competition between take-the-best and three well-known learning algorithms [nearest neighbor classifier, Quinlan's decision-tree induction algorithm C4.5, and classification and regression tree (CART)], also including a greedy version of take-the-best (TTB) that orders cues by conditional validity instead of unconditional validity. Mean predictive accuracy in cross-validation is plotted as a function of the sample size of the training set. The two tasks were deciding $(A)$ which of two German cities has more inhabitants, and $(B)$ which of two mammal species lives longer on average (Brighton \& Gigerenzer 2011).

strategies (Figure 1). This suggests that the predictive power of take-the-best stems mostly from the search rule rather than the stopping rule.

The ecological rationality of take-the-best has been studied in three different situations: (a) when the cue order is known (Katsikopoulos \& Martignon 2006, Martignon \& Hoffrage 2002), (b) when error is introduced in that knowledge (Hogarth \& Karelaia 2007), and (c) when the order of cues needs to be inferred from samples (Brighton 2006, Gigerenzer \& Brighton 2009). Taken together, these results suggest two structures of environments that take-the-best can exploit: moderate to high cue redundancy and moderate to high variability in cue weights.

Many experimental studies asked the descriptive question whether take-the-best can predict people's inferences (e.g., Bröder 2003, Bröder \& Gaissmaier 2007, Bröder \& Schiffer 2006, Newell \& Shanks 2003, Rieskamp \& Hoffrage 1999). Dieckmann \& Rieskamp (2007) first showed that in environments with high redundancy, take-the-best is as accurate as and more frugal than naive Bayes (a strategy that integrates all cues), and then experimentally demonstrated that in highredundancy environments, take-the-best predicted participants' judgments best, whereas in low-redundancy environments, compensatory strategies predicted best, indicating adaptive strategy selection. Rieskamp \& Otto (2006) showed that in an environment with high variability of cue validities, judgments consistent with take-the-best increased over experimental trials from $28 \%$ to $71 \%$, whereas in an environment with low variability, they decreased to $12 \%$. Bröder (2003) reported similar selection of take-the-best dependent on the variability or cue validities. In several experiments, individuals classified as take-the-best users for tasks where the heuristic is ecologically rational showed higher IQs than those who were classified as compensatory decision makers, suggesting that cognitive capacity as measured by IQ "is not consumed by strategy execution, but rather by strategy selection" (Bröder \& Newell 2008, p. 209). 
Bergert \& Nosofsky (2007) formulated a stochastic version of take-the-best, tested it against a weighted additive model at the individual level, and concluded that the vast majority of participants adopted the take-thebest heuristic. Comparing take-the-best with both weighted additive and exemplar models of categorization, Nosofsky \& Bergert (2007) found that most participants did not use an exemplar-based strategy but instead followed the response time predictions of take-the-best. Bröder \& Gaissmaier (2007) analyzed five published experiments and one new experiment, and reported that in all instances when decision outcomes indicated the use of take-the-best, decision times increased monotonically with the number of cues that had to be searched in memory, as predicted by take-the-best's search and stopping rules. Taken together, these studies indicate systematic individual differences in strategy use and adaptive use of take-the-best.

García-Retamero \& Dhami (2009) tested how policemen, professional burglars, and laypeople infer which of two residential properties is more likely to be burgled. Both expert groups' inferences were best modeled by take-the-best, and laypeople's inferences by a weighted additive rule. The latter may reflect that laypeople need to explore all the information, whereas experts know what is relevant, consistent with findings of the literature on expertise (Ericsson et al. 2007, Reyna \& Lloyd 2006, Shanteau 1992).

Concerns were raised by Juslin \& Persson (2002) that take-the-best is not so simple after all but requires complex computations for ordering the cues; Dougherty et al. (2008) and Newell (2005) voiced similar concerns. First, it is true that estimating validity order can sometimes be nontrivial, yet it is simpler than estimating other kinds of weights such as regression weights. Second, people estimate order from samples rather than by calculating the "true" order from perfect knowledge about the entire population, as Juslin and Persson assumed. Even with minute sample sizes of two to ten-resulting in estimated orders that deviate from the true order-take-the-best predicted more accurately than multiple regression when both were provided with continuous cue values (Katsikopoulos et al. 2010). Finally, a person does not need to learn cue orders individually but instead can learn from others, as through teaching and imitation (Gigerenzer et al. 2008).

Consumer choice. How do consumers decide which product to buy among an ever-increasing assortment on the Internet or on supermarket shelves? The classical methodology to answer this question has been conjoint analysis, which assumes a weighted linear combination of features or cues. When John Hauser, a proponent of conjoint analysis, began to test models of heuristics, he found to his surprise that sequential heuristics predict consumer choices well (Hauser et al. 2009). Examples are decisions between computers (Kohli \& Jedidi 2007) and smartphones (Yee et al. 2007). In particular, heuristics are important early in the decision process to form a consideration set, which consists of eliminating most products from further consideration. Once the consideration set is formed, consumers evaluate the remaining options more carefully (Gaskin et al. 2007; see also Reisen et al. 2008). Within their consideration set of potential suppliers, they then appear to trade off price and reliability to reach their final choice.

Literature search. How should an organization design a search algorithm for prioritizing literature searches from the PsycINFO database? Lee and colleagues (2002) engineered two methods for identifying articles relevant to a given topic of interest (e.g., eyewitness testimony), one a variant of take-the-best, the other a Bayesian model using all available information. Lee et al. tested both methods on ten actual literature searches and measured the methods' performances against effort (i.e., the proportion of the articles read by the user) and accuracy (i.e., proportion of relevant articles found). The variant of take-the-best was as good as or better than the Bayesian model, particularly in searches in which the proportion of relevant articles was small. 


\section{Fast-and-Frugal Trees}

One way to model classification is in terms of trees. For instance, Bayes' rule can be represented as a tree with $2^{m}$ leaves, where $m$ is the number of binary cues or attributes. Natural frequencies provide such a representation. Yet when the number of cues grows, a Bayesian analysis-with or without natural frequencies-becomes computationally intractable or fraught with estimation error because one typically has too few data points for the thousands of leaves of such a gigantic tree. A fast-and-frugal tree has only $m+1$ leaves and thus is likely more robust. It has building blocks similar to take-the-best (Martignon et al. 2003):

1. Search rule: Search through cues in a predetermined order.

2. Stopping rule: Stop search as soon as a cue leads to an exit.

3. Decision rule: Classify the object accordingly.

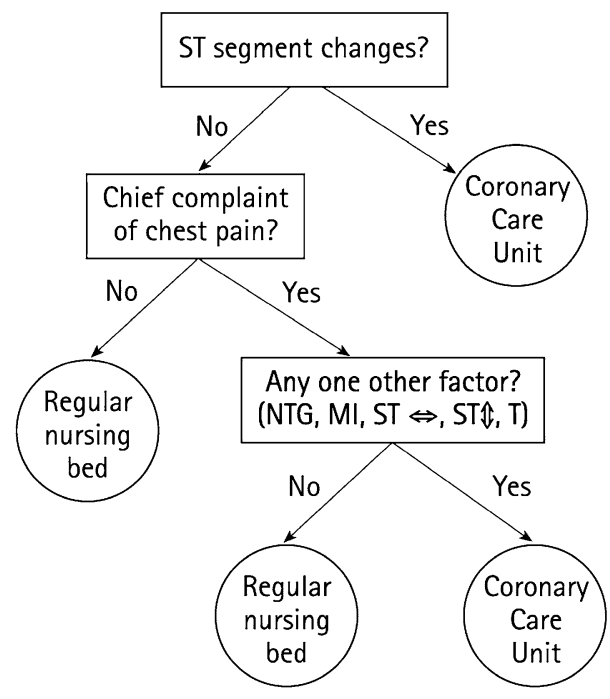

Fast-and-frugal trees are used by experts in many fields, from emergency screening to bail decisions (see Figure 2). Martignon et al. (2008) tested the accuracy of fast-and-frugal trees in 30 classification problems from fields such as medicine, sports, and economics. They reported that complex benchmark strategies including logistic regression excelled in data fitting, but fast-and-frugal trees were close or identical to these strategies in their predictive accuracy.

Emergency medicine. When patients arrive at the hospital with severe chest pain, emergency physicians have to decide quickly whether they suffer from acute ischemic heart disease and should be assigned to the intensive coronary care unit (ICU). In a Michigan hospital, doctors preferred to err on what they believed was the safe side by sending about $90 \%$ of the patients to the ICU, although only about $25 \%$ of these actually had a myocardial

Figure 2

Fast-and-frugal trees for medical and legal decisions. The tree on the left prescribes how emergency physicians can detect acute ischemic heart disease. It only asks up to three yes/no questions, namely whether the patient's electrocardiogram shows a certain anomaly ("ST segment changes"), whether chest pain is the patient's primary complaint, and whether there is any other factor (Green \& Mehr 1997). The tree on the right describes how magistrates at a London court decided whether to bail a defendant or to react punitively by imposing conditions such as curfew or imprisonment. The logic is defensive and "passes the buck." The tree predicted 92\% of bail decisions correctly (Dhami 2003). Abbreviations: MI, myocardial infarction; N.A., not applicable; NTG, nitroglycerin; $\mathrm{T}$, $\mathrm{T}$-waves with peaking or inversion. 
infarction (Green \& Mehr 1997). The result was an overly crowded ICU, a decrease in quality of care, an increase in cost, and a risk of serious infection among those who were incorrectly assigned. Something had to be done. Green \& Mehr (1997) tried two solutions: (a) a logistic regression, the Heart Disease Predictive Instrument (HDPI), and (b) a fast-and-frugal tree. To use the HDPI, doctors received a chart with some 50 probabilities, checked the presence and absence of symptoms, and inserted the relevant probabilities into a pocket calculator. The fast-and-frugal tree ignored all probabilities and asked only a few yes-or-no questions (Figure 2). Ultimately, the tree was more accurate in predicting actual heart attacks than the HDPI: It sent fewer patients who suffered from a heart attack wrongly into a regular bed and also nearly halved physicians' high false-alarm rate. Last but not least, the tree was transparent, easy to memorize, and easy to modify, and was accepted by physicians who disliked relying on a logistic regression they barely understood.

Easy memorization is an important feature of fast-and-frugal trees, particularly in emergency situations. After the terrorist attacks on September 11, 2001, START (Simple Triage and Rapid Treatment; Cook 2001) helped paramedics to quickly classify victims into two major categories: those who needed medical treatment immediately and those whose treatment could be delayed. A tree with only two cues-age and duration of fever-was developed to decide upon macrolide prescription in young children with community-acquired pneumonia (Fischer et al. 2002). This tree was slightly less accurate than a scoring system based on logistic regression ( $72 \%$ versus $75 \%$ ), but it does not require any expensive technology and thus can be applied to millions of children worldwide who would otherwise not have access to healthcare.

How to model physicians' thinking? Taking for granted that physicians use heuristics for diagnosing patients, the medical community quickly adopted the heuristics-and-biases view and has left it mainly unrevised as of today
(Croskerry 2009). For instance, Elstein (1999) described heuristics as "mental shortcuts commonly used in decision making that can lead to faulty reasoning or conclusions" (p. 791) and blamed them for many errors in clinical reasoning. Some researchers, however, recognize their potential to improve decisions. McDonald (1996), for one, wrote, "admitting the role of heuristics confers no shame" (p. 56). Rather, the goal should be to formalize and understand heuristics so that their use can be effectively taught, which could lead to less practice variation and more efficient medical care. "The next frontier will involve fast and frugal heuristics; rules for patients and clinicians alike" (Elwyn et al. 2001, p. 358).

For diagnosis, which is a form of classification, fast-and-frugal trees potentially model how physicians make decisions. For treatment choice, all heuristics described above are potential models. Both fast-and-frugal trees and other heuristics differ from traditional models of medical decision making, such as logistic regression for classification and expected utility maximization for choice. Dhami \& Harries (2001) compared a fast-and-frugal tree ("matching heuristic") to a linear regression model on general practitioners' decisions to prescribe lipid-lowering drugs for a set of hypothetical patients. Both models fitted prescription decisions equally well, but the simple tree relied on less information. Similar results were obtained by Smith \& Gilhooly (2006) and Backlund et al. (2009). These studies reported only fitting-not predictingphysicians' judgments, which is a limitation. More direct evidence comes from the routine use of fast-and-frugal trees by physicians in cancer screening and HIV tests.

Bail decisions. Heuristics matter in the law in multiple respects. They play a role in the making of law (Haidt et al. 2006) as well as in litigation (Hastie \& Wittenbrink 2006). In both domains, there has been debate whether heuristics are a problem or a solution (Gigerenzer \& Engel 2006). 
One of the initial decisions of the legal system is whether to bail a defendant unconditionally or to react punitively by conditions such as curfew or imprisonment. In England and Wales, around two million bail decisions are made every year by benches of two or three magistrates, $99.9 \%$ of whom are members of the local community without legal training. How do they make these decisions? When magistrates were interviewed, they generally responded that they thoroughly examined and weighed all information in a complex way (Dhami \& Ayton 2001). However, when Dhami (2003) observed several hundreds of trials in two London courts, she found that the average time magistrates spent on a case was 6 to 10 minutes and that their decisions could be predicted better with a fast-and-frugal tree ("matching heuristic") than with weighting and adding all information (Figure 2). The logic of the tree appears to be to "pass the buck," because it copies the punitive decisions of the prosecution, a previous court, or the police. It violates due process because it ignores relevant information about the defendant. In the two courts, the fast-and-frugal trees predicted $92 \%$ and $85 \%$ of all decisions correctly (crossvalidation), compared to $86 \%$ and $73 \%$ by a weighted additive model that would correspond to due process and what magistrates responded in the interviews.

\section{TRADE-OFF HEURISTICS}

Unlike recognition-based and one-reason decisions, the third class of heuristics weights cues or alternatives equally and thus makes trade-offs (compensatory strategies).

\section{Tallying}

Whereas take-the-best ignores cues (but includes a simple form of weighting cues by ordering them), tallying ignores weights, weighting all cues equally. It entails simply counting the number of cues favoring one alternative in comparison to others.
1. Search rule: Search through cues in any order.

2. Stopping rule: Stop search after $m$ out of a total of $M$ cues (with $1<m \leq M$ ). If the number of positive cues is the same for both alternatives, search for another cue. If no more cues are found, guess.

3. Decision rule: Decide for the alternative that is favored by more cues.

Dawes (1979; Dawes \& Corrigan 1974) showed that tallying was about as accurate as multiple regression and sometimes even better. In a more extensive test across 20 environments, Czerlinski et al. (1999) demonstrated that tallying had, on average, a higher predictive accuracy than multiple regression. The challenge is to figure out when this is the case. Einhorn \& Hogarth (1975) found that unit-weight models were successful in comparison to multiple regression when the ratio of alternatives to cues was 10 or smaller, the linear predictability of the criterion was small $\left(R^{2} \leq 0.5\right)$, and cues were highly redundant. Relatively few studies have identified conditions under which people would use a tallying strategy. Interestingly, it seems that more people prefer to dispense with particular cues (as in one-reason decision making) than with cue order or weights (Bröder \& Schiffer 2003, Rieskamp \& Hoffrage 2008; but see Wang 2008). One reason for the relatively low prevalence of tallying could be that these studies used only few cues, typically four or five. Below we provide two illustrations of the prescriptive use of tallying in institutions (for more, see Astebro \& Elhedhli 2006, Graefe \& Armstrong 2009, Lichtman 2008, Wang 2008).

Magnetic Resonance Imaging (MRI) or simple bedside rules? There are about 2.6 million emergency room visits for dizziness or vertigo in the United States every year (Kattah et al. 2009). The challenging task for the emergency physician is to detect the rare cases where dizziness is due to a dangerous brainstem or cerebellar stroke. Frontline misdiagnosis of strokes happens in about $35 \%$ of the cases. One solution to this challenge could be technology. Getting an early MRI with
Trade-offs: a class of heuristics that weights all cues or alternatives equally and thus makes trade-offs (e.g., tallying and $1 / \mathrm{N}$ ) 
diffusion-weighted imaging takes 5 to 10 minutes plus several hours of waiting time, costs more than $\$ 1,000$, and is not readily available everywhere. However, Kattah et al. (2009) developed a simple bedside eye exam that actually outperforms MRI and takes only about one minute: It consists of three tests and raises an alarm if at least one indicates a stroke. This simple tallying rule correctly detected $100 \%$ of those patients who actually had a stroke (sensitivity), whereas an early MRI only detected $88 \%$. Out of 25 patients who did not have a stroke, the bedside exam raised a false alarm in only one case (i.e., $4 \%$ false positive rate $=96 \%$ specificity). Even though the MRI did not raise any false alarms, the bedside exam seems preferable in total, given that misses are more severe than false alarms and that it is faster, cheaper, and universally applicable.

Avoiding avalanche accidents. Hikers and skiers need to know when avalanches could occur. The obvious clues method is a tallying heuristic that checks how many out of seven cues have been observed en route or on the slope that is evaluated (McCammon \& Hägeli 2007). These cues include whether there has been an avalanche in the past 48 hours and whether there is liquid water present on the snow surface as a result of recent sudden warming. When more than three of these cues are present on a given slope, the situation should be considered dangerous. With this simple tallying strategy, $92 \%$ of the historical accidents (where the method would have been applicable) could have been prevented.

\section{Mapping Model}

How do people arrive at quantitative estimates based on cues? The mapping model assumes that people tally the number of relevant cues with an object's positive values (von Helversen \& Rieskamp 2008). The estimate is the median criterion value of objects with the same number of positive cues. The mapping model captured people's judgment better than a linear regression and an exemplar model when the criterion values followed a skewed distribution.
Sentencing decision. In the adversarial U.S. legal system, the vast majority of cases are closed by plea bargaining, where the prosecution and defense negotiate a sentence, which is then ratified by a judge. In contrast, in Germany and many other countries, plea bargaining before a case goes to court is an exception rather than the rule. Here, the judge has to determine an appropriate sentence proportional to the offender's guilt, within the range of the minimum and maximum sentence specified for each offense. The single most important factor influencing judges' decisions is the prosecution's sentencing recommendation. How should the prosecution make its recommendation? The German penal code lists over 20 factors to consider. The legal literature recommends a three-step strategy: Determine first all relevant factors and the direction of their effect on the sentence (aggravating or mitigating), then weight these by their importance, and add them up to determine the sentence. Von Helversen \& Rieskamp (2009) analyzed trial records of sentencing and tested five models of how sentencing decisions have been made in theft, fraud, and forgery, including a linear regression model. The best predictions of actual sentences were obtained by the mapping model, a heuristic model of quantitative estimation, based on a simple tallying rule described above. As von Helversen \& Rieskamp (2009) pointed out, this result "provides further evidence that legal decision makers rely heavily on simple decision heuristics... and suggests that eliciting these employed heuristics is an important step in understanding and improving legal decision making” (pp. 389-390).

\section{1/N Rule}

Another variant of the equal weighting principle is the $1 / N$ rule, which is a simple heuristic for the allocation of resources (time, money) to $N$ alternatives:

$1 / N$ rule: Allocate resources equally to each of $N$ alternatives.

This rule is also known as the equality heuristic (Messick 1993). Sharing an amount 
of money equally is the modal response in the one-shot ultimatum game for adults and also the most frequent split in children's group decisions, contrary to the predictions of game theory (Takezawa et al. 2006).

Investment. When deciding how to allocate financial resources among $N$ options, some individuals rely on the $1 / N$ rule (Benartzi \& Thaler 2001), which allocates financial resources equally across all alternatives. The $1 / N$ rule was compared to 14 optimizing models, including a Nobel Prize-winning model, Markowitz's mean-variance portfolio, in seven investment problems (DeMiguel et al. 2009). To estimate the models' parameters, each optimizing strategy received 10 years of stock data and then had to predict the next month's performance on this basis. The same procedure was repeated, with a moving window, for the next month, and so forth, until no data were left. Note that $1 / N$ does not have any free parameters that need to be estimated. Nevertheless, it came out first on certainty equivalent returns, second on turnover, and fifth on the Sharpe ratio. None of the complex optimizing models could consistently beat it.

\section{SOCIAL INTELLIGENCE}

According to the social intelligence hypothesis, also called the Machiavellian intelligence hypothesis (Whiten \& Byrne 1997), highly social species such as humans and other social primates should be intellectually superior to less social ones because the social environment is more complex, less predictable, and more intellectually challenging. In Humphrey's (1976/1988) words, social primates "must be able to calculate the consequences of their own behavior, to calculate the likely behaviours of others, to calculate the balance of advantage and loss" (p. 19). For the sake of argument, let us assume that the social world is indeed more complex and unpredictable than the nonsocial one. Would social intelligence therefore require more complex cognition? Not necessarily, according to the following two hypotheses (Hertwig \& Herzog 2009):

1. Social intelligence does not require complex mental calculation; it also works with heuristics.

2. The same heuristics that underlie nonsocial decision making also apply to social decisions (but not vice versa).

The justification for hypothesis 1 is the same as for complex nonsocial problems: The more unpredictable a situation is, the more information needs to be ignored to predict the future. One reason for hypothesis 2 is that the distinction between social and nonsocial is a common oversimplification in the first place. Nevertheless, for the purpose of this review, we distinguish two meanings of social: whether the input into a strategy is social information (e.g., when imitating the behavior of a peer) or not (e.g., features of digital cameras), and whether the task is a game against nature or a social game involving other humans (Hertwig et al. 2011). The goals of social intelligence go beyond accuracy, frugality, and making fast decisions. They include transparency, group loyalty, and accountability (Lerner \& Tetlock 1999). Consistent with hypothesis 2 , heuristics from all three classes discussed above have been investigated in social situations. Below are a few examples.

\section{Recognition-Based Decisions}

Reimer \& Katsikopoulos (2004) first showed analytically that less-is-more effects are larger in group decisions than in individual decisions and subsequently demonstrated this effect empirically in an experiment in which another fascinating phenomenon emerged. Consider a group of three in which one member recognized only city $a$ while the other two members recognized both cities $a$ and $b$ and individually chose $b$ as the larger one. The majority rule predicts that $b$ would always be selected, yet in $59 \%$ of the cases, the final group decision was $a$, following the one who had not heard of $b$. 


\section{One-Reason Decision Making}

As mentioned above, the behavior of most people in the one-shot ultimatum game is inconsistent with the classical economic predictions. Most researchers nevertheless retained the utility-maximizing framework and added free parameters for other-regarding dispositions (e.g., Fehr \& Schmidt 1999). In contrast, Rubinstein (2003) called for a radical change, "to open the black box of decision making, and come up with some completely new and fresh modeling devices" (p. 1215). Fischbacher and colleagues (2011) did so and modeled the individual differences observed in the ultimatum game by fast-and-frugal trees of different sizes, involving one to four cues. The number of cues predicted how long decisions took.

\section{Trade-Off Heuristics}

Many parents try to divide their time every day between their $N$ children equally by $1 / N$. If parents have only two children, $1 / N$ will attain the long-term goal of providing each child with as much time as the other. But if there are three or more children (excepting multiple births), only the first-born and last-born have exclusive time with the parents, while the middle-borns have to share with their siblings throughout their childhood and thus end up receiving less time in total. The simple $1 / N$ rule predicts a complex pattern of care time for each child, a pattern observed in a survey of 1,296 families (Hertwig et al. 2002). This result illustrates that a heuristic and its goal (fair division during childhood) are not the same-the environment has the last word. The majority rule is a second example of a tallying rule applied to group decisions; it also defines democratic voting systems (Hastie \& Kameda 2005).

\section{Social Heuristics}

Although the heuristics discussed so far can be fed with both social and nonsocial information, there are genuinely social heuristics designed exclusively for social information. Examples include imitation heuristics, tit-for-tat, the social-circle heuristic, and averaging the judgments of others to exploit the "wisdom of crowds" (Hertwig \& Herzog 2009). Imitatethe-successful, for instance, speeds up learning of cue orders and can find orders that excel take-the-best's validity order (GarciaRetamero et al. 2009). Social heuristics prove particularly helpful in situations in which the actor has little knowledge. The classic example is that of Francis Galton, who visited a livestock fair where villagers estimated the weight of an ox and was surprised to find that their median and mean average estimates were only 9 and 1 pounds, respectively, off the actual weight of 1198 pounds (Galton 1907).

A peculiar social rule is the default heuristic: "If there is a default, do nothing about it." Defaults are set by institutions and act as implicit recommendations (Johnson \& Goldstein 2003). Every year, an estimated 5,000 Americans and 1,000 Germans die while waiting for a suitable organ donor. Although most citizens profess that they approve of organ donation, relatively few sign a donor card: only about $28 \%$ and $12 \%$ in the United States and Germany, respectively. In contrast, $99.9 \%$ of the French and Austrians are potential donors. These striking differences can be explained by the default heuristic. In explicit-consent societies such as Germany, the law prescribes that nobody is a donor unless one opts in. In presumed-consent societies such as France, the default is that everyone is a donor unless one opts out. Although most people appear to follow the same heuristic, the result is drastically different because the legal environment differs.

Very few studies use large-scale demographic data to test social heuristics. For instance, marriage patterns are studied by demographers without much attention to the social heuristics that generate these, and vice versa. Todd and colleagues (2005) had the ingenious methodological insight that the aggregate demographic data rule out certain heuristics and can be used to test various satisficing strategies for mate choice. 


\section{Moral Behavior}

Although moral behavior has long been attributed to conscious reflection, Haidt \& Bjorklund (2008) argued that reasons are typically used to justify behavior after the fact and that the causes are mostly unconscious or intuitive. Gigerenzer (2010) proposed that these unconscious causes are often social heuristics, such as imitating the behavior of peers in order to gain acceptance by the group. Note that one and the same social heuristic can lead to behavior evaluated as moral or immoral, such as when imitating benevolent or malevolent peer behavior. This perspective on moral behavior is different from assuming that people have internalized specific moral rules such as don't steal and don't kill.

Moral behavior has been related to "sacred values" (Fiske \& Tetlock 1997). If one understands sacred values as top cues in lexicographic heuristics, decisions between alternatives where a sacred value conflicts with a secular value (e.g., life versus money) should be faster and easier than when two sacred values (e.g., one life versus another) conflict with each other, as reported by Hanselmann \& Tanner (2008). Baron \& Ritov (2009) argued that, from a utilitarian perspective, this form of one-reason decision making can cause great problems for policy decisions as it could prevent trade-offs for the greater good. In the same vein, Sunstein (2005) asserted that moral heuristics can lead to great error, but added that we would not necessarily "be better off without them. On the contrary, such heuristics might well produce better results, from the moral point of view, than the feasible alternatives" (p. 535). Cosmides \& Tooby (2006) located the origins of moral heuristics in our ancestral world of tiny bands of individuals. An example of a moral heuristic is an intuitive search rule that looks for information that could reveal whether one has been cheated in a social contract. This heuristic correctly predicts when information search in the Wason selection task contradicts propositional logic (Gigerenzer 2000).

\section{CONCLUSIONS}

We began this review with the observation that the three major tools for modeling decision making-logic, statistics, and heuristics-have not been treated equally, with each suited to a particular kind of problem. Instead, in psychology, heuristics became associated with errors and contrasted with logical and statistical rules that were believed to define rational thinking in all situations. Yet this view has been questioned for uncertain, large worlds where the assumptions of rational models are not met. We reviewed studies on decisions by individuals and institutions, including business, medical, and legal decision making, that show that heuristics can often be more accurate than complex "rational" strategies. This puts heuristic on a par with statistical methods and emphasizes a new ecological question: In what environment does a given strategy (heuristic or otherwise) succeed? This insight adds a prescriptive research program to that of the existing descriptive research program on heuristics. Pioneers such as Dawes, Hogarth, and Makridakis demonstrated years ago that simple forecasting methods can often predict better than standard statistical procedures; as James March, one of the most influential researchers in organizational decision making, put it more than 30 years ago, "If behavior that apparently deviates from standard procedures of calculated rationality can be shown to be intelligent, then it can plausibly be argued that models of calculated rationality are deficient not only as descriptors of human behavior but also as guides to intelligent choice" (1978, p. 593).

Nonetheless, a large community continues to routinely model behavior with complex statistical procedures without testing these against simple rules. Yet a fundamental change in thinking about human and animal behavior seems to be occurring. Mathematical biologists McNamara \& Houston (2009) described this shift: "Although behavioral ecologists have built complex models of optimal behavior in simple environments, we argue that they need 
to focus on simple mechanisms that perform well in complex environments" (p. 675).

Formal models also help to answer the descriptive question of when people rely on what heuristic. As for the prescriptive question, a similar conflict is waged between those who argue in favor of classical statistical techniques as models of the mind (typically weighting and adding of all information) and those who argue that many people consistently rely on heuristics. The best way to decide is comparative testing; the difficulty is to understand the individual differences reported in most experiments.

With all these new insights, we are left with big challenges. How should we develop a systematic theory of the building blocks of heuristics and the core capacities as well as environmental structures that these exploit?
To what extent can the emerging science of heuristic decision making provide a unifying framework for the study of the mind? One way to proceed is theory integration, that is, to connect the simple heuristics framework with other theoretical frameworks in psychology. This is already happening with ACT-R (Adaptive Control of Thought-Rational) theory (Schooler \& Hertwig 2005), signal detection theory (Luan et al. 2010, Pleskac 2007), and the heuristics-and-biases program (Read \& Grushka-Cockayne 2010). In physics, theory integration, such as quantum theory and relativity theory, is a primary goal. In psychology, theory integration is not accorded the importance it deserves; instead, the field still resembles a colorful loose patchwork. We envision that the study of cognitive heuristics may help to sew some of the pieces together.

\section{SUMMARY POINTS}

1. Heuristics can be more accurate than more complex strategies even though they process less information (less-is-more effects).

2. A heuristic is not good or bad, rational or irrational; its accuracy depends on the structure of the environment (ecological rationality).

3. Heuristics are embodied and situated in the sense that they exploit core capacities of the brain and their success depends on the structure of the environment. They provide an alternative to stable traits, attitudes, preferences, and other internal explanations of behavior.

4. With sufficient experience, people learn to select proper heuristics from their adaptive toolbox.

5. Usually, the same heuristic can be used both consciously and unconsciously, for inferences and preferences, and underlies social as well as nonsocial intelligence.

6. Decision making in organizations typically involves heuristics because the conditions for rational models rarely hold in an uncertain world.

\section{FUTURE ISSUES}

1. How do people learn, individually or socially, to use heuristics in an adaptive way? And what prevents them from doing so? (For a start: Rieskamp \& Otto 2006)

2. Does intelligence mean knowing when to select which strategy from the adaptive toolbox? (For a start: Bröder \& Newell 2008) 
3. Are gut feelings based on heuristics, and if so, on which? (For a start: Gigerenzer 2007)

4. To what extent is moral (and immoral) behavior guided by social heuristics? (For a start: Gigerenzer 2010, Sunstein 2005)

5. How does the content of the adaptive toolbox change over the life span and between cultures? (For a start: Mata et al. 2007)

6. Can people adapt the use of heuristics to idiosyncrasies in their core capacities, such as differences in memory span, but also differences in knowledge? (For a start: Bröder \& Gaissmaier 2007)

7. Which heuristics do humans share with which animals, and why? (For a start: Hutchinson \& Gigerenzer 2005 and commentaries)

8. Finally, the overarching goal: Develop a systematic theory of the building blocks of cognitive heuristics (such as search, stopping, and decision rules) anchored in core capacities and the social and physical structures they exploit.

\section{ACKNOWLEDGMENTS}

We thank Mirta Galesic, Sebastian Hafenbrädl, Ralph Hertwig, Ulrich Hoffrage, Konstantinos Katsikopoulos, Julian N. Marewski, and Lael J. Schooler for helpful comments, and Rona Unrau for editing the manuscript.

\section{DISCLOSURE STATEMENT}

The authors are not aware of any affiliations, memberships, funding, or financial holdings that might be perceived as affecting the objectivity of this review.

\section{LITERATURE CITED}

Alter AL, Oppenheimer DM. 2006. Predicting short-term stock fluctuations by using processing fluency. Proc. Natl. Acad. Sci. USA 103:9369-72

Astebro T, Elhedhli S. 2006. The effectiveness of simple decision heuristics: forecasting commercial success for early-stage ventures. Manage. Sci. 52:395-409

Attneave E. 1953. Psychological probability as a function of experienced frequency. F. Exp. Psychol. 46:81-86

Ayton P, Fischer I. 2004. The hot hand fallacy and the gambler's fallacy: two faces of subjective randomness? Mem. Cogn. 32:1369-78

Backlund LG, Bring J, Skaner Y, Strender L-E, Montgomery H. 2009. Improving fast and frugal in relation to regression analysis: test of 3 models for medical decision making. Med. Decis. Making 29:140-48

Baron J, Ritov I. 2009. Protected values and omission bias as deontological judgments. In The Psychology of Learning and Motivation. Vol. 50: Moral fudgment and Decision Making, ed. DM Bartels, CW Bauman, LJ Skitka, DL Medin, pp. 133-67. San Diego, CA: Academic

Baucells M, Carrasco JA, Hogarth RM. 2008. Cumulative dominance and heuristic performance in binary multiattribute choice. Oper. Res. 56:1289-304

Benartzi S, Thaler RH. 2001. Naïve diversification strategies in defined contribution saving plans. Am. Econ. Rev. 91:79-98

Bergert FB, Nosofsky RM. 2007. A response-time approach to comparing generalized rational and take-thebest models of decision making. F. Exp. Psychol:: Learn. Mem. Cogn. 331:107-29

Binmore K. 2009. Rational Decisions. Princeton, NJ: Princeton Univ. Press 
Boyd M. 2001. On ignorance, intuition and investing: a bear market test of the recognition heuristic. F. Psychol. Finan. Market. 2:150-56

Brighton H. 2006. Robust inference with simple cognitive models. In Between a Rock and a Hard Place: Cognitive Science Principles Meet AI-Hard Problems. Papers from the AAAI Spring Symposium (AAAI Tech. Rep. No. SS-06-03), ed. C Lebiere, B Wray, pp. 17-22. Menlo Park, CA: AAAI Press

Brighton H, Gigerenzer G. 2008. Bayesian brains and cognitive mechanisms: harmony or dissonance? In The Probabilistic Mind: Prospects for Bayesian Cognitive Science, ed. N Chater, M Oaksford, pp. 189-208. New York: Oxford Univ. Press

Brighton H, Gigerenzer G. 2011. How heuristics exploit uncertainty. In Ecological Rationality: Intelligence in the World, ed. PM Todd, G Gigerenzer, ABC Res. Group. New York: Oxford Univ. Press. In press

Bröder A. 2003. Decision making with the "adaptive toolbox": influence of environmental structure, intelligence, and working memory load. F. Exp. Psychol.: Learn. Mem. Cogn. 29:611-25

Bröder A, Gaissmaier W. 2007. Sequential processing of cues in memory-based multi-attribute decisions. Psychon. Bull. Rev. 14:895-900

Bröder A, Newell BR. 2008. Challenging some common beliefs: empirical work within the adaptive toolbox metaphor. Fudgm. Decis. Mak. 3:205-14

Bröder A, Schiffer S. 2003. Take the best versus simultaneous feature matching: probabilistic inferences from memory and effects of representation format. 7. Exp. Psychol:: Gen. 132:277-93

Bröder A, Schiffer S. 2006. Stimulus format and working memory in fast and frugal strategy selection. F. Behav. Decis. Mak. 19:361-80

Bröder A, Schütz J. 2009. Recognition ROCs are curvilinear—or are they? On premature arguments against the two-high-threshold model of recognition. 7. Exp. Psychol.: Learn. Mem. Cogn. 35:587-606

Chater N, Oaksford M, Nakisa R, Redington M. 2003. Fast, frugal and rational: how rational norms explain behavior. Organ. Behav. Hum. Decis. Process. 90:63-86

Coates SL, Butler LT, Berry DC. 2004. Implicit memory: a prime example for brand consideration and choice. Appl. Cogn. Psychol. 18:1195-211

Cook L. 2001. The World Trade Center attack. The paramedic response: an insider's view. Crit. Care 5:301-3

Cosmides L, Tooby J. 2006. Evolutionary psychology, moral heuristics, and the law. See Gigerenzer \& Engel 2006, pp. 175-205

Croskerry P. 2009. A universal model of diagnostic reasoning. Acad. Med. 84:1022-28

Czerlinski J, Gigerenzer G, Goldstein DG. 1999. How good are simple heuristics? See Gigerenzer et al. 1999, pp. $97-118$

Dawes RM. 1979. The robust beauty of improper linear models in decision making. Am. Psychol. 34:571-82

Dawes RM, Corrigan B. 1974. Linear models in decision making. Psychol. Bull. 81:95-106

DeMiguel V, Garlappi L, Uppal R. 2009. Optimal versus naive diversification: How inefficient is the 1/N portfolio strategy? Rev. Financ. Stud. 22:1915-53

Dhami MK. 2003. Psychological models of professional decision making. Psychol. Sci. 14:175-80

Dhami MK, Ayton P. 2001. Bailing and jailing the fast and frugal way. F. Behav. Decis. Mak. 14:141-68

Dhami MK, Harries C. 2001. Fast and frugal versus regression models of human judgment. Think. Reasoning $7: 5-27$

Dieckmann A, Rieskamp J. 2007. The influence of information redundancy on probabilistic inferences. Mem. Cogn. 35:1801-13

Dougherty MR, Franco-Watkins AM, Thomas R. 2008. Psychological plausibility of the theory of probabilistic mental models and the fast and frugal heuristics. Psychol. Rev. 115:199-213

Einhorn HJ, Hogarth RM. 1975. Unit weighting schemes for decision making. Organ. Behav. Hum. Decis. Process. 13:171-92

Elstein AS. 1999. Heuristics and biases: selected errors in clinical reasoning. Acad. Med. 74:791-94

Elwyn G, Edwards A, Eccles M, Rovner D. 2001. Decision analysis in patient care. Lancet 358:571-74

Ericsson KA, Prietula MJ, Cokely ET. 2007. The making of an expert. Harv. Bus. Rev. 85:114-21

Evans JS. 2008. Dual-processing accounts of reasoning, judgment, and social cognition. Annu. Rev. Psychol. 59:255-78

Fehr E, Schmidt KM. 1999. A theory of fairness, competition, and cooperation. Q. F. Econ. 114:817-68 
Fischbacher U, Hertwig R, Bruhin U. 2011. How simple heuristics embody social intelligence in games. In Social Heuristics That Make Us Smart, ed. R Hertwig, U Hoffrage, ABC Res. Group. New York: Oxford Univ. Press. In press

Fischer JE, Steiner F, Zucol F, Berger C, Martignon L, et al. 2002. Use of simple heuristics to target macrolide prescription in children with community-acquired pneumonia. Arch. Pediatr. Adolesc. Med. 156:1005-8

Fishburn PC. 1974. Lexicographic orders, utilities and decision rules: a survey. Manage. Sci. 20:1442-71

Fiske AP, Tetlock PE. 1997. Taboo trade-offs: reactions to transactions that transgress the spheres of justice. Polit. Psychol. 18:255-97

Frosch C, Beaman CP, McCloy R. 2007. A little learning is a dangerous thing: an experimental demonstration of ignorance-driven inference. Q. 7. Exp. Psychol. 60:1329-36

Gaissmaier W, Marewski JN. 2010. Forecasting elections with mere recognition from lousy samples A comparison of collective recognition, wisdome of crowds, and representative polls. J udgm. D edis. M ak. In press

Galton F. 1907. Vox populi. Nature 75:7

García-Retamero R, Dhami MK. 2009. Take-the-best in expert-novice decision strategies for residential burglary. Psychon. Bull. Rev. 16:163-69

García-Retamero R, Takezawa M, Gigerenzer G. 2009. Does imitation benefit cue order learning? Exp. Psychol. 56:307-20

Gaskin S, Evgeniou T, Bailiff D, Hauser J. 2007. Two-stage models: identifying noncompensatory heuristics for the consideration set then adaptive polyhedral methods within the consideration set. Proc. Sawtooth Software Conf. 13:67-83

Geman S, Bienenstock E, Doursat R. 1992. Neural networks and the bias/variance dilemma. Neural Comput. 4:1-58

Gigerenzer G. 1991. From tools to theories: a heuristic of discovery in cognitive psychology. Psychol. Rev. 98:254-67

Gigerenzer G. 2000. Adaptive Thinking: Rationality in the Real World. New York: Oxford Univ. Press

Gigerenzer G. 2007. Gut Feelings: The Intelligence of the Unconscious. New York: Viking

Gigerenzer G. 2008. Rationality for Mortals: How People Cope with Uncertainty. New York: Oxford Univ. Press

Gigerenzer G. 2010. Moral satisficing: rethinking moral behavior as bounded rationality. Topics Cogn. Sci. 2:528-54

Gigerenzer G, Brighton H. 2009. Homo heuristicus: why biased minds make better inferences. Topics Cogn. Sci. 1:107-43

Gigerenzer G, Engel C. 2006. Heuristics and the Law. Cambridge, MA: MIT Press

Gigerenzer G, Goldstein DG. 1996. Reasoning the fast and frugal way: models of bounded rationality. Psychol. Rev. 104:650-69

Gigerenzer G, Hoffrage U, Goldstein DG. 2008. Fast and frugal heuristics are plausible models of cognition: reply to Dougherty, Franco-Watkins, and Thomas. Psychol. Rev. 115:230-39

Gigerenzer G, Todd PM, ABC Res. Group. 1999. Simple Heuristics That Make Us Smart. New York: Oxford Univ. Press

Glöckner A, Betsch T, Schindler N. 2010. Coherence shifts in probabilistic inference tasks. F. Bebav. Decis. $M a k$. In press

Goldstein DG, Gigerenzer G. 2002. Models of ecological rationality: the recognition heuristic. Psychol. Rev. 109:75-90

Goldstein DG, Gigerenzer G. 2009. Fast and frugal forecasting. Int. F. Forecast. 25:760-72

Graefe A, Armstrong J. 2009. Forecasting elections from voters' perceptions of candidates' ability to handle issues. http://ssrn.com/abstract $\mathbf{= 1 2 0 6 6 8 3}$

Green L, Mehr DR. 1997. What alters physicians' decisions to admit to the coronary care unit? F. Fam. Pract. 45:219-26

Groner M, Groner R, Bischof WF. 1983. Approaches to heuristics: a historical review. In Methods of Heuristics, ed. R Groner, pp. 1-18. Hillsdale, NJ: Erlbaum

Haidt J, Baer S, Cosmides L, Epstein RA, Fikentscher W, et al. 2006. What is the role of heuristics in making law? See Gigerenzer \& Engel 2006, pp. 239-57 
Haidt J, Bjorklund F. 2008. Social intuitionists answer six questions about moral psychology. In Moral Psychology: Vol. 2. The Cognitive Science of Morality: Intuition and Diversity, ed. W Sinnott-Armstrong, pp. 181-217. Cambridge, MA: MIT Press

Hammond KR. 2007. Beyond Rationality: The Search for Wisdom in a Troubled Time. Oxford, UK: Oxford Univ. Press

Hanselmann M, Tanner C. 2008. Taboos and conflicts in decision making: sacred values, decision difficulty, and emotions. Fudgm. Decis. Mak. 3:51-63

Hastie R, Kameda T. 2005. The robust beauty of majority rules in group decisions. Psychol. Rev. 112:494-508

Hastie R, Wittenbrink B. 2006. Heuristics for applying laws to facts. See Gigerenzer \& Engel 2006, pp. 259-80

Hauser JR, Ding M, Gaskin SP. 2009. Non-compensatory (and compensatory) models of consideration-set decisions. In Proceedings of the Sawtooth Software Conference, Delray Beach, FL

Hepler TJ. 2008. Decision-making in sport: an examination of the take the first heuristic and self-efficacy theory. Doctoral dissert., Michigan State Univ.

Hertwig R, Davis JN, Sulloway FJ. 2002. Parental investment: how an equity motive can produce inequality. Psychol. Bull. 128:728-45

Hertwig R, Gigerenzer G, Hoffrage U. 1997. The reiteration effect in hindsight bias. Psychol. Rev. 104:194-202

Hertwig R, Herzog SM, Schooler LJ, Reimer T. 2008. Fluency heuristic: a model of how the mind exploits a by-product of information retrieval. F. Exp. Psychol.: Learn. Mem. Cogn. 34:1191-206

Hertwig R, Herzog SM. 2009. Fast and frugal heuristics: tools of social rationality. Soc. Cogn. 27:661-98

Hertwig R, Hoffrage U, ABC Research Group. 2011. Social Heuristics That Make Us Smart. New York: Oxford Univ. Press

Hilbig BE, Pohl RF. 2008. Recognizing users of the recognition heuristic. Exp. Psycbol. 55:394-401

Hodgkinson GP, Healey MP. 2008. Cognition in organizations. Annu. Rev. Psychol. 59:387-417

Hogarth RM. 2011. When simple is hard to accept. In Ecological Rationality: Intelligence in the World, ed. PM Todd, G Gigerenzer, ABC Res. Group. Oxford, UK: Oxford Univ. Press. In press

Hogarth RM, Karelaia N. 2007. Heuristic and linear models of judgment: matching rules and environments. Psychol. Rev. 114:733-58

Holton G. 1988. Thematic Origins of Scientific Thought. Cambridge, MA: Harvard Univ. Press. 2nd ed.

Hoyer WD, Brown SP. 1990. Effects of brand awareness on choice for a common, repeat purchase product. 7. Consum. Res. 17:141-48

Humphrey N. 1976 /1988. The social function of intellect. In Machiavellian Intelligence, ed. R Byrne, A Whiten, pp. 13-26. Oxford, UK: Clarendon

Hutchinson JMC, Gigerenzer G. 2005. Simple heuristics and rules of thumb: where psychologists and behavioural biologists might meet. Behav. Processes 69:87-124

Jacoby LL, Dallas M. 1981. On the relationship between autobiographical memory and perceptual learning. 7. Exp. Psychol:: Gen. 110:306-40

Jacoby LL, Woloshyn V, Kelly CM. 1989. Becoming famous without being recognized: unconscious influences of memory produced by dividing attention. F. Exp. Psychol.: Gen. 118:115-25

Johnson EJ, Goldstein DG. 2003. Do defaults save lives? Science 302:1338-39

Johnson JG, Raab M. 2003. Take the first: option generation and resulting choices. Organ. Behav. Hum. Decis. Process. 91:215-29

Juslin P, Persson M. 2002. PROBabilities from EXemplars (PROBEX): a "lazy" algorithm for probabilistic inference from generic knowledge. Cogn. Sci. 26:563-607

Kahneman D. 2003. Maps of bounded rationality: a perspective on intuitive judgment and choice. In Les Prix Nobel: The Nobel Prizes 2002, ed. T Frangsmyr, pp. 449-89. Stockholm: Nobel Found.

Kahneman D, Frederick S. 2002. Representativeness revisited: attribute substitution in intuitive judgment. In Heuristics and Biases: The Psychology of Intuitive fudgment, ed. T Gilovich, D Griffin, D Kahneman, pp. 49-81. New York: Cambridge Univ. Press

Karelaia N. 2006. Thirst for confirmation in multi-attribute choice: Does search for consistency impair decision performance? Organ. Behav. Hum. Decis. Process. 100:128-43

Katsikopoulos KV, Martignon L. 2006. Naive heuristics for paired comparisons: some results on their relative accuracy. 7. Math. Psychol. 50:488-94 
Katsikopoulos KV, Schooler LJ, Hertwig R. 2010. The robust beauty of ordinary information. Psychol. Rev. In press

Kattah JC, Talkad AV, Wang DZ, Hsieh YH, Newman-Toker DE. 2009. HINTS to diagnose stroke in the acute vestibular syndrome. Three-step bedside oculomotor examination more sensitive than early MRI diffusion-weighted imaging. Stroke 40:3504-10

Keren G, Schul Y. 2009. Two is not always better than one. A critical evaluation of two-system theories. Perspect. Psychol. Sci. 4:533-50

Kleffner DA, Ramachandran VS. 1992. On the perception of shape from shading. Percept. Psychophys. 52:18-36

Klein G. 2004. The Power of Intuition: How to Use Your Gut Feelings to Make Better Decisions at Work. New York: Currency/Doubleday

Kohli R, Jedidi K. 2007. Representation and inference of lexicographic preference models and their variants. Market. Sci. 26:380-99

Lee MD, Cummins TDR. 2004. Evidence accumulation in decision making: unifying the "take the best" and the "rational" models. Psychon. Bull. Rev. 11:343-52

Lee MD, Loughlin N, Lundberg IB. 2002. Applying one reason decision-making: the prioritisation of literature searches. Aust. 7. Psychol. 54:137-43

Lerner JS, Tetlock PE. 1999. Accounting for the effects of accountability. Psychol. Bull. 125:255-75

Lichtman AJ. 2008. The keys to the White House: an index forecast for 2008. Int. F. Forecast. 24:301-9

Luan S, Schooler L, Gigerenzer G. 2010. A signal detection analysis of fast-and-frugal trees. Manuscr. under revision

Luce RD. 1956. Semiorders and a theory of utility discrimination. Econometrica 24:178-91

March JG. 1978. Bounded rationality, ambiguity, and the engineering of choice. Bell f. Econ. 9:587-608

Marewski JN. 2010. On the theoretical precision, and strategy selection problem of a single-strategy approach: a comment on Glöckner, Betsch, and Schindler. 7. Behav. Decis. Mak. In press

Marewski JN, Gaissmaier W, Schooler LJ, Goldstein DG, Gigerenzer G. 2010. From recognition to decisions: extending and testing recognition-based models for multi-alternative inference. Psychon. Bull. Rev. 17:287309

Marewski JN, Schooler LJ. 2010.Cognitive niches: An ecological model of emergent strategy selection. Manuscr. submitted

Martignon L, Hoffrage U. 2002. Fast, frugal, and fit: simple heuristics for paired comparisons. Theory Decis. 52:29-71

Martignon L, Katsikopoulos KV, Woike J. 2008. Categorization with limited resources: a family of simple heuristics. F. Math. Psychol. 52:352-61

Martignon L, Vitouch O, Takezawa M, Forster M. 2003. Naive and yet enlightened: from natural frequencies to fast and frugal trees. In Thinking: Psychological Perspectives on Reasoning, Fudgment, and Decision Making, ed. D Hardman, L Macchi, pp. 189-211. Chichester, UK: Wiley

Mata R, Schooler LJ, Rieskamp J. 2007. The aging decision maker: cognitive aging and the adaptive selection of decision strategies. Psychol. Aging 22:796-810

McCammon I, Hägeli P. 2007. An evaluation of rule-based decision tools for travel in avalanche terrain. Cold Reg. Sci. Tech. 47:193-206

McDonald C. 1996. Medical heuristics: the silent adjudicators of clinical practice. Ann. Intern. Med. 124:56-62

McGrath RE. 2008. Predictor combination in binary decision-making situations. Psychol. Assess. 20:195-205

McLeod P, Dienes Z. 1996. Do fielders know where to go to catch the ball or only how to get there? 7. Exp. Psychol.: Hum. Percept. Perform. 22:531-43

McNamara JM, Houston AI. 2009. Integrating function and mechanism. Trends Ecol. Evol. 24:670-75

Messick DM. 1993. Equality as decision heuristic. In Psychological Perspectives on fustice: Theory and Application, ed. BA Mellers, J Baron, pp. 11-31. New York: Cambridge Univ. Press

Newell BR. 2005. Re-visions of rationality. Trends Cogn. Sci. 9:11-15

Newell BR, Fernandez D. 2006. On the binary quality of recognition and the inconsequentiality of further knowledge: two critical tests of the recognition heuristic. 7. Behav. Decis. Mak. 19:333-46

Newell BR, Rakow T, Weston NJ, Shanks DR. 2004. Search strategies in decision-making: the success of "success." 7. Behav. Decis. Mak. 17:117-37

Newell BR, Shanks DR. 2003. Take the best or look at the rest? Factors influencing "one-reason" decision making. 7. Exp. Psychol.: Learn. Mem. Cogn. 29:53-65 
Nosofsky RM, Bergert FB. 2007. Limitations of exemplar models of multi-attribute probabilistic inference. 7. Exp. Psychol.: Learn. Mem. Cogn. 33:999-1019

Oppenheimer D. 2003. Not so fast! (and not so frugal!): rethinking the recognition heuristic. Cognition 90:B1-9

Ortmann A, Gigerenzer G, Borges B, Goldstein DG. 2008. The recognition heuristic: a fast and frugal way to investment choice? In Handbook of Experimental Economics Results: Vol. 1 (Handbooks in Economics No. 28), ed. CR Plott, VL Smith, pp. 993-1003. Amsterdam: North Holland

Pachur T, Biele G. 2007. Forecasting from ignorance: the use and usefulness of recognition in lay predictions of sports events. Acta Psychol. 125:99-116

Pachur T, Bröder A, Marewski JN. 2008. The recognition heuristic in memory-based inference: Is recognition a noncompensatory cue? 7. Behav. Decis. Mak. 21:183-210

Pachur T, Hertwig R. 2006. On the psychology of the recognition heuristic: retrieval primacy as a key determinant of its use. F. Exp. Psychol: Learn. Mem. Cogn. 32:983-1002

Pachur T, Mata R, Schooler LJ. 2009. Cognitive aging and the adaptive use of recognition in decision making. Psychol. Aging 24:901-15

Pachur T, Todd PM, Gigerenzer G, Schooler LJ, Goldstein DG. 2011. When is the recognition heuristic an adaptive tool? In Ecological Rationality: Intelligence in the World, ed. PM Todd, G Gigerenzer, ABC Res. Group. New York: Oxford Univ. Press. In press

Parikh J. 1994. Intuition: The New Frontier of Management. Oxford, UK: Blackwell Business

Payne JW, Bettman JR, Johnson EJ. 1993. The Adaptive Decision Maker. New York: Cambridge Univ. Press

Petrie M, Halliday T. 1994. Experimental and natural changes in the peacock's (Pavo cristatus) train can affect mating success. Behav. Ecol. Sociobiol. 35:213-17

Pitt MA, Myung IJ, Zhang S. 2002. Toward a method for selecting among computational models for cognition. Psychol. Rev. 109:472-91

Pleskac TJ. 2007. A signal detection analysis of the recognition heuristic. Psychon. Bull. Rev. 14:37-91

Pohl R. 2006. Empirical tests or the recognition heuristic. F. Behav. Decis. Mak. 19:251-71

Ratcliff R, McKoon G. 1989. Similarity information versus relational information: differences in the time course of retrieval. Cogn. Psychol. 21:139-55

Read D, Grushka-Cockayne Y. 2010. The similarity heuristic. 7. Behav. Decis. Mak. In press

Reimer T, Katsikopoulos K. 2004. The use of recognition in group decision-making. Cogn. Sci. 28:1009-29

Reisen N, Hoffrage U, Mast FW. 2008. Identifying decision strategies in a consumer choice situation. Fudgm. Decis. Mak. 3:641-58

Reyna VF, Lloyd FJ. 2006. Physician decision making and cardiac risk: effects of knowledge, risk perception, risk tolerance, and fuzzy processing. 7. Exp. Psychol. Appl. 12:179-95

Richter T, Späth P. 2006. Recognition is used as one cue among others in judgment and decision making. 7. Exp. Psychol.: Learn. Mem. Cogn. 32:150-62

Rieskamp J, Hoffrage U. 1999. When do people use simple heuristics, and how can we tell? See Gigerenzer et al. 1999 , pp. 141-67

Rieskamp J, Hoffrage U. 2008. Inferences under time pressure: how opportunity costs affect strategy selection. Acta Psychol. 127:258-76

Rieskamp J, Otto P. 2006. SSL: a theory of how people learn to select strategies. F. Exp. Psychol.: Gen. 135:20736

Rossmo DK. 2005. Geographic heuristics or shortcuts to failure? A response to Snook et al. 2004. Appl. Cogn. Psychol. 19:651-54

Rubinstein A. 2003. Economics and psychology? The case of hyperbolic discounting. Int. Econ. Rev. 44:120716

Savage LJ. 1954. The Foundations of Statistics. New York: Dover. 2nd ed.

Scheibehenne B, Bröder A. 2007. Predicting Wimbledon 2005 tennis results by mere player name recognition. Int. 7. Forecast. 23:415-26

Schmitt M, Martignon L. 2006. On the complexity of learning lexicographic strategies. F. Mach. Learn. Res. 7:55-83

Schmittlein DC, Peterson RA. 1994. Customer base analysis: an industrial purchase process application. Market. Sci. 13:41-67 
Schooler LJ, Hertwig R. 2005. How forgetting aids heuristic inference. Psychol. Rev. 112:610-28

Sedlmeier P, Hertwig R, Gigerenzer G. 1998. Are judgments of the positional frequencies of letters systematically biased due to availability? f. Exp. Psychol.: Learn. Mem. Cogn. 24:754-70

Seeley TD. 2001. Decision making in superorganisms: how collective wisdom arises from the poorly informed masses. In Bounded Rationality: The Adaptive Toolbox, ed. G Gigerenzer, R Selten, pp. 249-61. Cambridge, MA: MIT Press

Serwe S, Frings C. 2006. Who will win Wimbledon? The recognition heuristic in predicting sports events. 7. Behav. Decis. Mak. 19:321-32

Shaffer DN, Krauchunas SM, Eddy M, McBeath MK. 2004. How dogs navigate to catch Frisbees. Psychol. Sci. $15: 437-41$

Shah AK, Oppenheimer DM. 2008. Heuristics made easy: an effort-reduction framework. Psychol. Bull. $137: 207-22$

Shanteau J. 1992. How much information does an expert use? Is it relevant? Acta Psychol. 81:75-86

Shepard RN. 2001. Perceptual-cognitive universals as reflections of the world. Behav. Brain Sci. 24:581-601

Simon HA. 1955. A behavioral model of rational choice. Q. F. Econ. 69:99-118

Simon HA. 1979. Rational decision making in business organizations. Am. Econ. Rev. 69:493-513

Simon HA. 1989. The scientist as problem solver. In Complex Information Processing: The Impact of Herbert A. Simon, ed. D Klahr, K Kotovsky, pp. 373-98. Hillsdale, NJ: Erlbaum

Simon HA. 1990. Invariants of human behavior. Annu. Rev. Psychol. 41:1-19

Simon HA. 1992. What is an "explanation" of behavior? Psychol. Sci. 3:150-61

Simon HA. 1999. Appraisal. See Gigerenzer et al. 1999, back cover

Smith L, Gilhooly K. 2006. Regression versus fast and frugal models of decision-making: the case of prescribing for depression. Appl. Cogn. Psychol. 20:265-74

Smith VL. 2003. Constructivist and ecological rationality in economics. Am. Econ. Rev. 93:465-508

Snook B, Taylor PJ, Bennell C. 2004. Geographic profiling: the fast, frugal and accurate way. Appl. Cogn. Psychol. 18:105-21

Snook B, Zito M, Bennell C, Taylor PJ. 2005. On the complexity and accuracy of geographic profiling strategies. 7. Quant. Criminol. 21:1-26

Sorros G. 2009. The Crash of 2008 and What It Means: The New Paradigm for Financial Markets. New York: Public Affairs

Stiglitz JE. 2010. Freefall: America, Free Markets, and the Sinking of the World Economy. New York: Norton

Sunstein CR. 2005. Moral heuristics. Behav. Brain Sci. 28:531-73

Takezawa M, Gummerum M, Keller M. 2006. A stage for the rational tail of the emotional dog: roles of moral reasoning in group decision making. F. Econ. Psychol. 27:117-39

Todd PM, Billari F, Simão J. 2005. Aggregate age-at-marriage patterns from individual mate-search heuristics. Demography 42:559-74

Todd PM, Dieckmann A. 2005. Heuristics for ordering cue search in decision making. In Advances in Neural Information Processing Systems, vol. 17, ed. LK Saul, Y Weiss, L Bottou, pp. 1393-400. Cambridge, MA: MIT Press

Todd PM, Gigerenzer G, ABC Res. Group. 2011. Ecological Rationality: Intelligence in the World. New York: Oxford Univ. Press

Tversky A. 1972. Elimination by aspects: a theory of choice. Psychol. Rev. 79:281-99

Tversky A. 1977. Features of similarity. Psychol. Rev. 84:327-52

Tversky A, Kahneman D. 1973. Availability: a heuristic for judging frequency and probability. Cogn. Psychol. $5: 207-32$

Tversky A, Kahneman D. 1974. Judgment under uncertainty: heuristics and biases. Science 185:1124-30

Volz KG, Schooler LJ, Schubotz RI, Raab M, Gigerenzer G, von Cramon DY. 2006. Why you think Milan is larger than Modena: neural correlates of the recognition heuristic. 7. Cogn. Neurosci. 18:1924-36

von Helversen B, Rieskamp J. 2008. The mapping model: a cognitive theory of quantitative estimation. F. Exp. Psychol:: Gen. 137:73-96

von Helversen B, Rieskamp J. 2009. Predicting sentencing for low level crimes: comparing models of human judgment. 7. Exp. Psychol. Appl. 15:375-95 
Wang XT. 2008. Decision heuristics as predictors of public choice. 7. Behav. Decis. Mak. 21:77-89

Weber EU, Johnson EJ. 2009. Mindful judgment and decision making. Annu. Rev. Psychol. 60:53-86

Whiten A, Byrne RW. 1997. Machiavellian Intelligence II: Evaluations and Extensions. New York: Cambridge Univ. Press

Wübben M, von Wangenheim F. 2008. Instant customer base analysis: managerial heuristics often "get it right." F. Mark. 72:82-93

Yee M, Dahan E, Hauser J, Orlin J. 2007. Greedoid-based noncompensatory inference. Market. Sci. 26:532-49

Yonelinas AP, Otten LJ, Shaw KN, Rugg MD. 2005. Separating the brain regions involved in recollection and familiarity in recognition memory. 7. Neurosci. 25:3002-8

Zajonc RB. 1968. Attitudinal effects of mere exposures. F. Personal. Soc. Psychol. 9:1-27 
舟

Annual Review of Psychology

Volume 62, 2011

\section{Contents}

\section{Prefatory}

The Development of Problem Solving in Young Children:

A Critical Cognitive Skill

Rachel Keen

Decision Making

The Neuroscience of Social Decision-Making

James K. Rilling and Alan G. Sanfey

Speech Perception

Speech Perception

Arthur G. Samuel

Attention and Performance

A Taxonomy of External and Internal Attention

Marvin M. Chun, Julie D. Golomb, and Nicholas B. Turk-Browne

Language Processing

The Neural Bases of Social Cognition and Story Comprehension

Raymond A. Mar 103

Reasoning and Problem Solving

Causal Learning and Inference as a Rational Process:

The New Synthesis

Keith 7. Holyoak and Patricia W. Cheng

Emotional, Social, and Personality Development

Development in the Early Years: Socialization, Motor Development, and Consciousness

Claire B. Kopp 165

Peer Contagion in Child and Adolescent Social and Emotional Development Thomas 7. Dishion and Fessica M. Tipsord 189 


\section{Adulthood and Aging}

Psychological Wisdom Research: Commonalities and Differences in a Growing Field

Ursula M. Staudinger and Fudith Glück

Development in the Family

Socialization Processes in the Family: Social and

Emotional Development

Joan E. Grusec

Psychopathology

Delusional Belief

Max Coltheart, Robyn Langdon, and Ryan McKay

Therapy for Specific Problems

Long-Term Impact of Prevention Programs to Promote Effective Parenting: Lasting Effects but Uncertain Processes

Irwin N. Sandler, Erin N. Schoenfelder, Sharlene A. Wolchik, and David P. MacKinnon

Self and Identity

Do Conscious Thoughts Cause Behavior?

Roy F. Baumeister, E.7. Masicampo, and Kathleen D. Vobs

Neuroscience of Self and Self-Regulation

Todd F. Heatherton

Attitude Change and Persuasion

Attitudes and Attitude Change

Gerd Bohner and Nina Dickel

Cross-Country or Regional Comparisons

Culture, Mind, and the Brain: Current Evidence and Future Directions

Shinobu Kitayama and Ayse K. Uskul

Cognition in Organizations

Heuristic Decision Making

Gerd Gigerenzer and Wolfgang Gaissmaier

Structures and Goals of Educational Settings

Early Care, Education, and Child Development

Deborah A. Phillips and Amy E. Lowenstein 


\section{Psychophysiological Disorders and Psychological Dimensions on Medical Disorders}

Psychological Perspectives on Pathways Linking Socioeconomic Status and Physical Health Karen A. Matthews and Linda C. Gallo 501

Psychological Science on Pregnancy: Stress Processes, Biopsychosocial Models, and Emerging Research Issues Cbristine Dunkel Schetter

\section{Research Methodology}

The Development of Autobiographical Memory Robyn Fivush 559

The Disaggregation of Within-Person and Between-Person Effects in Longitudinal Models of Change Patrick 7. Curran and Daniel 7. Bauer

Thirty Years and Counting: Finding Meaning in the N400

Component of the Event-Related Brain Potential (ERP)

Marta Kutas and Kara D. Federmeier

\section{Indexes}

Cumulative Index of Contributing Authors, Volumes 52-62 ..................... 000

Cumulative Index of Chapter Titles, Volumes 52-62 .......................... 000

\section{Errata}

An online log of corrections to Annual Review of Psychology articles may be found at http://psych.AnnualReviews.org/errata.shtml 